\title{
Evolution of Microstructure and Crystallographic Texture During Dissimilar Friction Stir Welding of Duplex Stainless Steel to Low Carbon-Manganese Structural Steel
}

\author{
S. RAHIMI, T.N. KONKOVA, I. VIOLATOS, and T.N. BAKER
}

Electron backscattered diffraction (EBSD) was used to analyze the evolution of microstructure and crystallographic texture during friction stir welding of dissimilar type 2205 duplex stainless steel (DSS) to type S275 low carbon-manganese structural steel. The results of microstructural analyses show that the temperature in the center of stirred zone reached temperatures between $\mathrm{Ac}_{1}$ and $\mathrm{Ac}_{3}$ during welding, resulting in a minor ferrite-to-austenite phase transformation in the S275 steel, and no changes in the fractions of ferrite and austenite in the DSS. Temperatures in the thermomechanically affected and shoulder-affected zones of both materials, in particular toward the root of the weld, did not exceed the $\mathrm{Ac}_{1}$ of S275 steel. The shear generated by the friction between the material and the rotating probe occurred in austenitic/ferritic phase field of the S275 and DSS. In the former, the transformed austenite regions of the microstructure were transformed to acicular ferrite, on cooling, while the dual-phase austenitic/ferritic structure of the latter was retained. Studying the development of crystallographic textures with regard to shear flow lines generated by the probe tool showed the dominance of simple shear components across the whole weld in both materials. The ferrite texture in S275 steel was dominated by $D_{1}$, $D_{2}, E, \bar{E}$, and $F$, where the fraction of acicular ferrite formed on cooling showed a negligible deviation from the texture for the ideal shear texture components of bcc metals. The ferrite texture in DSS was dominated by $D_{1}, D_{2}, I, \bar{I}$, and $F$, and that of austenite was dominated by the $A, \bar{A}, B$, and $\bar{B}$ of the ideal shear texture components for bcc and fcc metals, respectively. While $D_{1}, D_{2}$, and $F$ components of the ideal shear texture are common between the ferrite in S275 steel and that of dual-phase DSS, the preferential partitioning of strain into the ferrite phase of DSS led to the development of $I$ and $\bar{I}$ components in DSS, as opposed to $E$ and $\bar{E}$ in the S275 steel. The formations of fine and ultrafine equiaxed grains were observed in different regions of both materials that are believed to be due to strain-induced continuous dynamic recrystallization (CDRX) in ferrite of both DSS and S275 steel, and discontinuous dynamic recrystallization (DDRX) in austenite phase of DSS.

https://doi.org/10.1007/s11661-018-5023-3

(C) The Author(s) 2018

S. RAHIMI and I. VIOLATOS are with the Advanced Forming Research Centre (AFRC), University of Strathclyde, 85 Inchinnan Drive, Inchinnan, Renfrew, PA4 9LJ, UK. Contact e-mail: salah.rahimi@strath.ac.uk, salah.rahimi@hotmail.co.uk T.N. KONKOVA is with the Department of Design, Manufacture and Engineering Management, University of Strathclyde, James Weir Building, 75 Montrose Street, Glasgow, G1 1XJ, UK. T.N. BAKER is with the Department of Mechanical and Aerospace Engineering, University of Strathclyde, James Weir Building, 75 Montrose Street, Glasgow, G1 1XJ, UK.

Manuscript submitted June 8, 2018.

Article published online November 29, 2018

\section{INTRODUCTION}

FRICTION stir welding (FSW) is a solid-state welding technique originally developed by The Welding Institute (TWI) in the early 1990s for joining aluminum alloys. $^{[1,2]}$ It has now become an important alternative process for joining aluminum alloys and also other alloying systems which are relatively soft compared to the tools used for stirring the material. ${ }^{[3-6]}$ FSW has also been developed for higher-temperature alloys including stainless steels, titanium and its alloys, low carbon microalloyed steel and other steels. ${ }^{[7-12]}$ However, the significantly high costs associated with tools for high melting point materials makes the process less economically competitive compared to the well-developed fusion welding processes, despite some efforts taken to 
overcome this issue through alternative methods. ${ }^{[13]}$ Due to the solid-state nature of the FSW, no macroscopic melting is involved for a wide range of alloys, and as a result, the rigorous controls normally needed in fusion welding to prevent solidification- and liquation-induced cracking, porosity and loss of volatile solutes, are not required. ${ }^{[5]}$ Also, the FS weld has improved mechanical and metallurgical properties, and normally a lower residual stress level than other methods of welding such as electron-beam welding, brazing, and weld cladding. ${ }^{[1-16]}$ Residual stress can provide enough driving force for the initiation and propagation of cracks that might lead to the failure in service. ${ }^{[17,18]}$

An extensive body of literature has been published on the viability of FSW for producing high quality defect free welds between dissimilar materials and alloys, ${ }^{[19-33]}$ in particular, those systems such as metal matrix composites that are difficult or impossible to weld by conventional fusion welding. ${ }^{[34-39]}$ The major difference between the FSW of similar and dissimilar materials is in the sharp discontinuity in properties across the weld cross section. This can result in asymmetric heat generation and materials flow behavior on both sides of the weld during the stirring process. Even in the case of joining similar materials by FSW, the weld region is not symmetrical relative to the center of the weld. ${ }^{[11]}$ This is primarily due to the nature of the stirring process that has both rotation and translation, which create advancing side (AS) and retreating side (RS) regions. The directions of rotation and translation on the AS are the same, and this results in a maximum relative velocity which leads to the highest plastic deformation compared to other regions of the weld. This also causes the temperature to be the highest on the AS. On the other hand, due to the opposite directions of rotation and translation, the minimum relative velocity occurs on the RS where the material is forced against the translation direction and results in maximized material mixing. ${ }^{[5,40-44]}$ Therefore, when joining dissimilar materials, taking into account the discontinuity in inherent material properties and the asymmetric nature of FSW, it is necessary to consider which side of the joint should contain the AS or RS, to achieve optimal mixing and superior properties.

Only a limited number of papers are available in public literature on the FSW of dissimilar steels. These include joints between AISI type 304 austenitic stainless steel and st37 steel under two different tool rotational speeds of 400 and $800 \mathrm{rpm},{ }^{[20]}$ joints between UNS S31603 austenitic stainless steel and UNS S32750 super-duplex stainless steel under various tool's rotational speeds (i.e., 100 to 300 $\mathrm{rpm}),{ }^{[45]}$ and a joint between a 2205 duplex stainless steel (DSS) and S275 low carbon-manganese structural steel. ${ }^{[4]}$ These studies have investigated the influence of welding parameters on the resultant microstructures, mechanical properties (e.g., yield stress, ultimate tensile strengths and elongation), bending endurance and fatigue performance. The microstructural studies of these welds reported the existence of heat affected zone (HAZ), thermomechanically affected zone (TMAZ) and stir zone
(SZ) on both sides of the joints, with the center of the welds having alternating bands of both materials. ${ }^{[20,45,46]}$ In the case of joining type 304 austenitic stainless steel to st37 steel, ${ }^{[20]}$ detailed microstructural analyses were carried out using a range of techniques and it was reported that the SZ had a mixed microstructure containing different types of ferrite with colonies of ferrite and cementite, indicating dynamic recrystallization in the SZ of type 304 stainless steel and phase transformation in that of st37 steel. ${ }^{[20]}$ For the other two dissimilar welds, ${ }^{[4,46]}$ the microstructural phases were characterized by optical microscopy and X-ray diffraction (XRD), and the observations used to justify the measured mechanical properties and performance. None of these studies however have reported texture evolution and the dominant deformation mechanisms during the welding process. As opposed to the FSW of dissimilar steels, a growing number of studies exist demonstrating successful FSW joints between similar superduplex stainless steel, ${ }^{[47]}$ UNS S31630 austenitic stainless steel, ${ }^{[48]}$ microalloyed steel ${ }^{[11,49,50]}$ pure iron, ${ }^{[10]}$ type 409 ferritic stainless steel $^{[51]}$ and type 304L stainless steel. ${ }^{[12]}$ Most of these studies emphasized on the inter-relationships between process parameters such as tool rotational and traverse speed, and the resultant microstructures, defect formation and mechanical properties of the welded joint, while the evolution of microstructure and crystallographic texture have received less attentions. This is most likely because using FSW for welding ferrous alloys with high melting points is challenging due to the high temperatures and critical wear conditions encountered by the rotating tools.

In general, the studies reported on microstructural evolution during FSW of ferrous systems with both face-centered cubic (FCC) and body-centered cubic (BCC) crystal structures, are mainly on materials in which the microstructure does not undergo solid-state phase transformation during welding. For example, the reports on the microstructure evolution during FSW of pure iron, ${ }^{[10]}$ type 409 ferritic stainless steel ${ }^{[51]}$ and the recrystallization behavior of type 304L stainless steel. ${ }^{[12]}$ The solid-state phase transformation influences the final microstructure, and in particular weakens the FSW-induced shear texture, thus making the recognition of dominant deformation mechanisms difficult or even impossible. The results of an investigation on API X 100 grade of linepipe steel ${ }^{[52]}$ in which phase transformation occurred during FSW, suggested that the material in TMAZ experienced a complex microstructure evolution. These are reported to be phase transformation in the SZ, continuous dynamic recrystallization in the transition zone between the TMAZ and the HAZ, and a rearrangement of low-angle grain boundaries in the HAZ. Given the severe shear deformation caused by FSW in the SZ, the measured crystallographic texture was random, and the reason for this observation was attributed to the weakening effect of phase transformation on the shear texture. ${ }^{[52]}$ However, a recent study on EH46 microalloyed steel, ${ }^{[11]}$ in which the SZ reached a temperature between $\mathrm{Ac}_{1}-\mathrm{Ac}_{3}$ during $\mathrm{FSW}$, caused a 
partial phase transformation resulting in a dual-phase austenitic/ ferritic microstructure during FSW, and showed the dominance of simple shear texture components across the whole weld. This study was even able to distinguish the $B\{1 \overline{1} 2\}\langle 110\rangle$ and $\bar{B}\{\overline{1} 1 \overline{1}\}\langle\overline{1} \overline{1} 0\rangle$ simple shear texture components which occurred in austenite portion at $\mathrm{Ac}_{1}-\mathrm{Ac}_{3}$ temperature through the bainite-phase textures formed on cooling that were inherited from the shear textures of the austenite phase showing a relatively strong variant selection. ${ }^{[11]}$ The ferrite portion of the SZ and that of the TMAZ were shown to undergo shear deformation with textures dominated by the $D_{1}\{\overline{1} \overline{1} 2\}\langle 111\rangle$ and $D_{2}\{11 \overline{2}\}\langle 111\rangle$ simple shear texture components. ${ }^{[1]}$ In addition to the phase transformation that might have an influence on changing the final crystallographic texture, extended plasticity mechanisms such as dynamic recrystallization active during the FSW process may also be influential. Observations of weak shear texture and rotated-cube texture in FCC materials imply the occurrence of these mechanisms during the process. ${ }^{[53]}$

Texture is a useful means of recognizing the major deformation mechanisms active during FSW. It is well understood that the shear created by the rotating tool is the main deformation mechanism causing microstructure and texture evolution during FSW. This has been seen during FSW of aluminum alloys in forms of the development of $\{110\}\langle 110\rangle$ and $\{114\}\langle 221\rangle$ shear texture components with respect to the local shear reference frame. ${ }^{[53,54]}$ A later study on aluminum revealed that the post-FSW texture was entirely formed of simple shear components, which are composed of $B / \bar{B}$ and $C$ with $B / \bar{B}$ in alternating bands across the whole weld. ${ }^{[55]}$ Similar observations were reported for Ti-6Al-4V ${ }^{[56]}$ and EH46 microalloyed steel ${ }^{[11]}$ where both materials undergo phase transformation during FSW, $\alpha \rightarrow \beta$ for the former and ferrite $\rightarrow$ austenite for the latter. Also, friction stir processing (FSP) has been seen to result in a well-defined $\{11 \overline{2}\}\langle 111\rangle$ shear texture in pure iron, ${ }^{[57]}$ and rotated-cube texture, $\{1 \overline{1} \overline{1}\}\langle 110\rangle,\{\overline{1} 12\}\langle 110\rangle$ and $\{001\}\langle 110\rangle$ in type 304 austenitic stainless steel. ${ }^{[5]}$

Dissimilar friction stir welding of duplex stainless steel (DSS) to low carbon-manganese structural steel, involves thermal effects, thermo mechanical processing and phase transformation depending on temperature, which still require thorough investigation. In particular, information is lacking on the evolution of microstructure and crystallographic texture during dissimilar FSW of these materials where DSS contains both ferrite and austenite phases with bcc and fcc crystal structures respectively, and structural steel has ferrite with bcc crystal structure. This is under a condition where a potential solid-state phase transformation in structural steel may occur during dissimilar FSW, dictating the physical and mechanical properties of ferrous alloys. This paper aims to present a clear understanding of the evolution of crystallographic texture and microstructural changes during dissimilar FSW of DSS 2205 to S275 low carbon-manganese structural steel.

\section{EXPERIMENTAL PROCEDURE}

\section{A. Material and Processing}

The weld was produced at TWI from two plates, one DSS 2205 and the other S275 low carbon-manganese structural steel, with identical dimensions of $2000 \mathrm{~mm} \times$ $200 \mathrm{~mm} \times 6 \mathrm{~mm}(L \times W \times T)$ that were butted together and clamped to the bed of the PowerStir ${ }^{\mathrm{TM}}$ FSW table. The chemical composition of both materials are provided in Table I. A typical PowerStir ${ }^{\mathrm{TM}}$ design MegaStir Q70 tool with convex scrolled shoulder and six sided tri-flat pin with $5.7 \mathrm{~mm}$ length was used with counter clock wise $(\mathrm{CCW})$ rotation direction. The pin geometry is a truncated tri-flat cone with a tapering angle alternating between $\approx 50$ and $60 \mathrm{deg}$ for the flat and curved sides, respectively.

The DSS was placed on the advancing side (AS) and the S275 low carbon-manganese structural steel on the retreating side (RS), where both the tool's rotation and traverse movement are in the same direction for the former, and in opposite directions (i.e., $180 \mathrm{deg}$ ) for the latter. The tool had a tungsten carbide shank with a probe made from polycrystalline boron nitride (PCBN) with tungsten (W)-rhenium (Re) binder. The weld was produced under force control in one pass with the FSW tool rotational speed of $200 \mathrm{rpm}$ and traverse speed of $100 \mathrm{~mm} \mathrm{~min}^{-1}$, under an average downward axial force of $55 \mathrm{kN}$, offset $0.6 \mathrm{~mm}$ toward the AS.

\section{B. Microstructure Characterization}

Optical microscopy (OM), scanning electron microscopy (SEM), and electron backscattered diffraction (EBSD) were used for microstructural characterization. For the EBSD analysis, a sample with $27 \mathrm{~mm} \times 6 \mathrm{~mm}$ dimensions was cut from the weld cross section, in the plane perpendicular to the welding direction (WD), and mechanically ground by silicon carbide ( $\mathrm{SiC}$ ) emery paper and polished by 6 and $1 \mu \mathrm{m}$ lubricate diamond paste and $0.05 \mu \mathrm{m}$ colloidal silica suspension, successively. The mirror-finished sample was then electropolished to remove approximately 20 to $30 \mu \mathrm{m}$ material from the mechanically polished surface using Struers' electrolyte A2 at ambient temperature for $45 \mathrm{~s}$ at $35 \mathrm{~V}$.

The acquisition of EBSD maps was carried out using a fully automated AZtec HKL Advanced (plus C5 Prem) Nordlys Max 2 EBSD system interfaced to a FEI Quanta-650 field-emission gun scanning electron microscope, with an accelerating voltage of $20 \mathrm{kV}$ and a 100 $\mu \mathrm{m}$ dia. aperture. The acquisition time was set to 30 milliseconds, collecting at least two frames for each point. Orientation mapping was performed across the weld in the probe dominated area, starting from the base material (BM) on far AS side (i.e., DSS side) and terminating on far RS side (i.e., S275 steel), with $0.5 \mu \mathrm{m}$ step size covering an area of $16 \mathrm{~mm} \times 0.5 \mathrm{~mm}$. Additionally, individual high resolution maps with 0.3 $\mu \mathrm{m}$ step size and $440 \mu \mathrm{m} \times 320 \mu \mathrm{m}$ area each, have been collected from the HAZ, TMAZ, and centerline of the SZ in the probe dominated area of the weld from both materials. The locations of these maps are highlighted in 
Figure 1. In all cases, a minimum of 80 pet of the scanned areas were indexed.

Following the EBSD scans, the surface was etched with a 4 pct nital solution for 15 seconds to reveal the microstructure of the S275 steel on the RS side for inspection by OM. This left the DSS on the AS side unaffected. The sample was then electroetched at ambient temperature for 30 seconds at $10 \mathrm{~V}$ in 10 pct oxalic acid electrolyte to highlight the duplex stainless steel microstructure for characterization by OM. This resulted in a grossly over-etched S275 carbon steel, while revealing the DSS microstructure.

\section{Residual Stress Measurement}

The surface residual stress maps were measured by X-ray diffraction (XRD) using a PROTO-LXRD diffractometer and the $\sin ^{2} \psi$ method. ${ }^{[59]}$ The measurements were in two perpendicular directions of the TD and the ND on the weld cross section. For these measurements, the stresses were calculated from the strains of the $\{211\}$ Bragg reflection in ferrite phase at $156^{\circ}$ Bragg angle, assuming X-ray elastic constants $S_{1}^{(h k l)}$ $(\mathrm{MPa})$ and $1 / 2 S_{2}^{(h k l)}(\mathrm{MPa})$ of $1.28 \times 10^{-6}$ and $5.92 \times 10^{-6}$, respectively. These measurements were performed on a rectangular grid at equally spaced points, $1 \mathrm{~mm}$ distance in both ND and TD, encompassing the entire weld and BM materials on either side of the weld. For each point in both directions, 11 measurements with 1-second exposure time for each measurement were performed. These were sufficient to obtain an adequate number of counts to construct strong peaks used for stress analyses. A round collimator with $1 \mathrm{~mm}$ radius and eleven $\psi$-off set angles in the range of maximum \pm 33 deg were employed.

\section{Microhardness Measurement}

After detailed microstructural characterization and residual stress determination, a hardness map of the weld cross section, including the BM and the different zones on both sides of the weld, was measured using a Struers Durascan 70 testing machine with a diamond shaped Vickers indenter by applying 1000 gf with 10 seconds delay. Indentations were made on a rectangular grid covering the weld cross section, with $0.5 \mathrm{~mm}$ spacing in both normal direction (ND) and transverse direction (TD) between indentations, and $\approx 250 \mu \mathrm{m}$ distance between the closest indentations and edges of the sample.

\section{RESULTS}

\section{A. Base Materials}

Figure 2(a) shows the OM appearance of the starting DSS material, an as-received, hot-rolled, and homogenization-treated plate, containing austenite in the form of predominantly elongated islands with complex morphology, embedded in ferrite matrix. The phase map obtained by EBSD (see Figure 2(c)) shows that the volume fractions of the ferrite (Red) and austenite (Blue) in the starting microstructure are approximately 64 and 36 pct, respectively. Both phases are elongated along the hot rolling direction (RD) with the average grain sizes of 5.8 and $4.2 \mu \mathrm{m}$, respectively, for the ferrite and austenite. The presence of annealing twin boundaries, depicted in white boundary traces in Figure 2(c), is visible inside the recrystallized austenite grains. Figure 2(b) shows orientation image map (OIM) of the starting DSS using inverse polefigure (IPF) coloring with respect to the normal direction (ND). The as-received DSS has a texture, which is presented in Figure 2(d) in the form of $\{011\}$ and $\{111\}$ polefigures, for both ferrite (i.e., bcc) and austenite (i.e., fcc) phases. BM has a relatively strong $\{001\}\langle 110\rangle$ orientation in the ferrite phase, and $\{110\}\langle 112\rangle$ orientation in the austenite where $\{h k l\}$ is the crystallographic plane perpendicular to the ND and $\langle u v w\rangle$ is the crystallographic direction parallel to the RD.

Figure 3(a) shows an OM of the starting S275 material, which consists of equiaxed ferrite grains with an average grain size of $10.3 \mu \mathrm{m}$, and pearlite colonies, with similar average grain size as that of the ferrite, distributed throughout the microstructure. A high resolution SEM micrograph of one of the pearlite colonies is shown in Figure 3(c). Figure 3(b) shows OIM of the S275 BM using IPF coloring with respect to the ND. The BM has a homogeneous microstructure with no texture, as shown in Figure 3(d) in the form of $\{011\}$ and $\{111\}$ polefigures. There are weak traces of $\langle 110\rangle$ poles parallel to the RD with heterogeneous distribution, indicating the presence of weak RD fibers, resulting from the manufacturing process.

\section{B. Weld Microstructure}

A low magnification OM appearance of the whole weld cross section after etching with 4 pct nital solution, to reveal S275 steel microstructure, is shown in Figure 1. The welded area in the etched S275 steel, located on the weld RS, can be distinguished from the BM by its characteristic truncated-cone shape. Since the 4 pct nital solution etching has left the DSS intact, the welded region of the DSS, located on the AS, is highlighted by superimposing dotted lines on the micrograph for more clarity. The line is drawn after electroetching with 10 pct oxalic acid, used to reveal the DSS microstructure, where the weld region was clearly identifiable from the rest of the DSS BM. Note that electroetching with oxalic acid resulted in a tarnish (i.e., over-etched) surface on the S275 steel, hence a requirement for two different stages of etching, one for each material. The slope of the weld in the probe dominated area varies between $50 \mathrm{deg}$ and $60 \mathrm{deg}$ from vertical, depending on distance from shoulder-affected zone (SAZ), due to the geometry of the tool. The slope of the weld on DSS side was measured to be $\approx 5 \mathrm{deg}$ lower than that of the S275 side. Highlighted in Figure 1, are the regions from which OM micrographs and EBSD maps were acquired and shown in Figures 4 through to Figure 6, Figures 9 and 10. 
Table I. Nominal Chemical Compositions of the Type 2205 DSS and the S275 Low Carbon-Manganese Structural Steel Used for Dissimilar FSW in This Study (Wt Pet)

\begin{tabular}{lccccccccc}
\hline Material & $\mathrm{Fe}$ & $\mathrm{Cr}$ & $\mathrm{Ni}$ & $\mathrm{Si}$ & $\mathrm{Mn}$ & $\mathrm{C}$ & $\mathrm{P}$ & $\mathrm{S}$ & Mo \\
\hline S275 & bal. & 0.09 & 0.16 & 0.16 & 0.47 & 0.1 & 0.023 & 0.033 & 0.03 \\
DSS & bal. & 22.53 & 5.69 & 0.56 & 0.77 & 0.019 & 0.018 & $<0.003$ & 3.0 \\
\hline
\end{tabular}

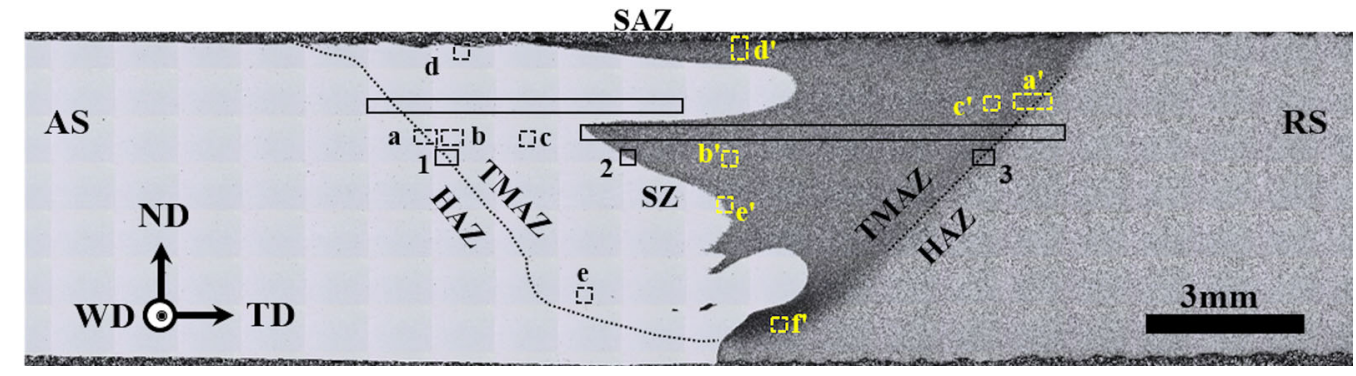

Fig. 1-Optical micrograph of the transverse cross section of the dissimilar friction stir weld between DSS and S275 steel. The micrograph is captured after etching with 4 pct nital solution to reveal the microstructure of S275 steel where the DSS side is non-etched (i.e., white region). The welding direction (WD) is perpendicular to the plane of the micrograph. DSS is on the AS, and S275 steel is on the RS. The two long rectangles indicate the positions of the long EBSD maps acquired from the BM of DSS across the weld through to the BM of S275. Locations labelled " $a$ " through " $e$ " are the positions of micrographs presented in Fig. 4(a) through $(e)$, respectively. Those labelled " $a$ " " through " $f$ " are the positions of micrographs presented in Fig. 5(a) through $(f)$, respectively. The solid squares labelled " 1 " through " 3 ", respectively show the positions of high resolution EBSD maps presented in Fig. 6(a) through $(c)$.

The stirring process has led to the formation of complex interlocking features at both macro- (see Figure 1) and microscales (see Figure 5(e)). The microinterlocking fingers of both materials are consistently in the order of few grains on either side of the weld interface (see Figure 5(e)). These interlocking features are predominantly in the probe dominated area in the middle of the SZ, and tend to disappear toward the root of the weld and regions closer to the SAZ. A thin layer of S275 steel, $\approx 100$ to $200 \mu \mathrm{m}$, is observed to be stirred to the very extreme of the SAZ on the DSS side, and vice versa a thin layer of DSS is stirred to the extreme of SAZ on the S275 steel side. Otherwise, no traces of either material is detected by $\mathrm{OM}$ to be incorporated by stirring in the other.

Micrographs taken after each etching stage are shown in Figures 4 and Figure 5 for the DSS and S275 steel, respectively. Figure 6 shows high resolution EBSD maps using IPF coloring with respect to the normal direction (ND), obtained from different regions of the weld highlighted in Figure 1. The microstructural examination revealed that the DSS side of the weld consists of the unchanged $\mathrm{BM}, \mathrm{HAZ}$, and TMAZ regions where the material was in direct contact with the probe during the FSW process (see Figures 4 and 6). The TMAZ can further be classified into subzones of SZ and SAZ on the basis of different microstructures, although differentiating SZ and SAZ from the TMAZ is not technically correct, because all of these zones undergo the stirring process. Figures 4(a) and 6(a) show the transition between the BM and HAZ of the weld in DSS side. In the HAZ, the austenite isles and the ferrite background appear to be reoriented from being parallel to the TD in the BM toward alignment with the tool's tapering angle with the ND. This reorientation is not consistent along HAZ/TMAZ interface as it has been seen to be pointing upward or downward, depending on the distance from the SAZ. For example, the micrograph in Figure 4(a) shows downward flow (i.e., reorientation) of grains, while the high resolution EBSD map of the HAZ/ TMAZ transition area presented in Figure 6(a), which is obtained from an area below that of Figure 4(a) (see Figure 1 for the positions), shows the upward flow of grains.

The TMAZ on the DSS side is a narrow band, $\approx 300$ to $400 \mu \mathrm{m}$, in which both the austenite isles and the ferrite matrix have a uniform equiaxed grain morphology with average grain sizes of 1 and $2 \mu \mathrm{m}$, respectively (see Figure 4(b)). The transition from TMAZ to SZ occurs sharply, where the microstructure differs from that of the TMAZ. In the SZ, although the average grain size of both ferrite and austenite phases is almost the same as those of TMAZ, the austenite colonies appear to grow larger (see Figure 4(c)). Similarly, the SAZ of the DSS has larger austenite colonies elongated along the direction of tool's shoulder rotation (see Figure 4(d)). The major difference in microstructure on the DSS side is observed in the TMAZ, toward the root of the weld where ultrafine grains are observed in both ferrite and austenite phases (see Figure 4(e)).

A detailed analysis of different regions of the S275 steel side of the weld by OM, shows that the BM microstructure extends into the HAZ, where clusters of fine grains $(\approx 4 \mu \mathrm{m})$ are observed weaved into the network of larger $(\approx 10$ to $11 \mu \mathrm{m})$ BM grains (see Figure 5(a)). The shorter the distance to the TMAZ, the greater becomes the volume fraction of small grain clusters. This microstructure is consistent along the 


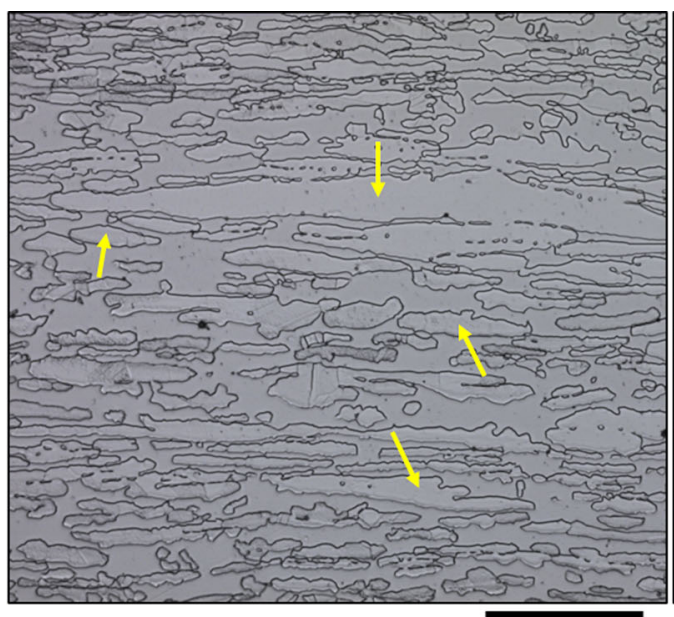

$50 \mu \mathrm{m}$

(a)

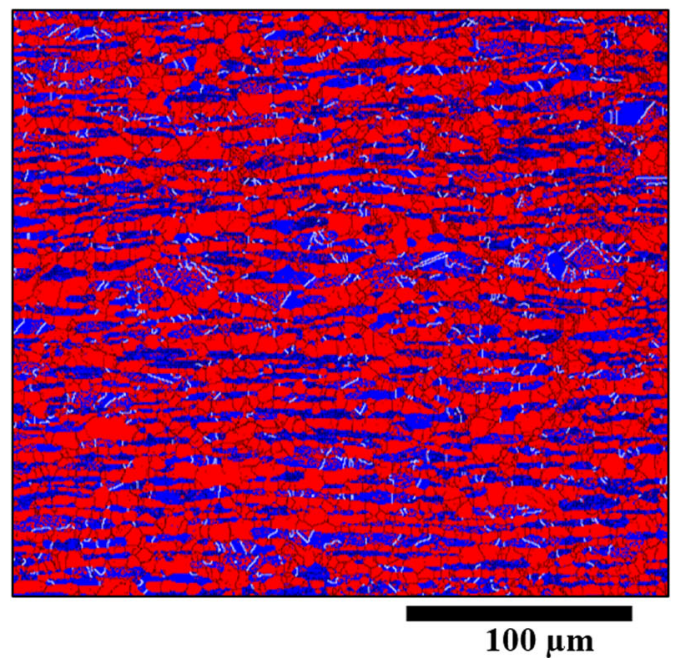

BCC, $64 \%$

FCC, $36 \%$

(c)

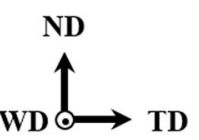

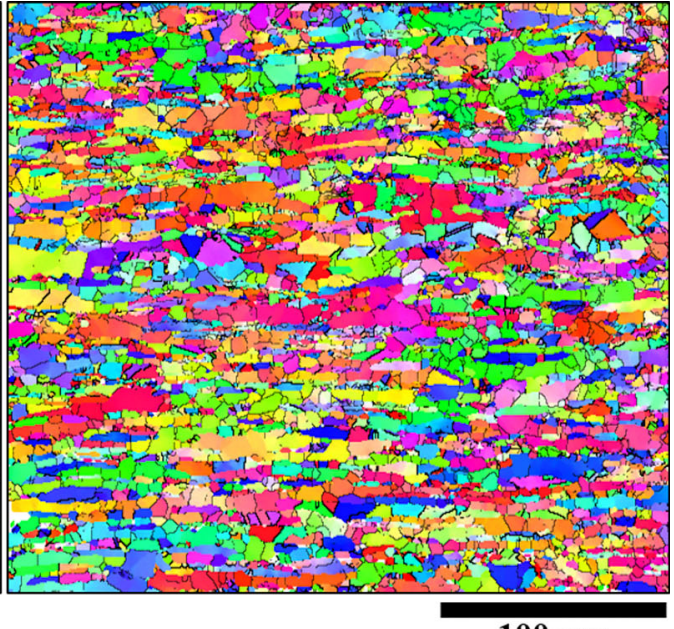

$100 \mu \mathrm{m}$

(b)
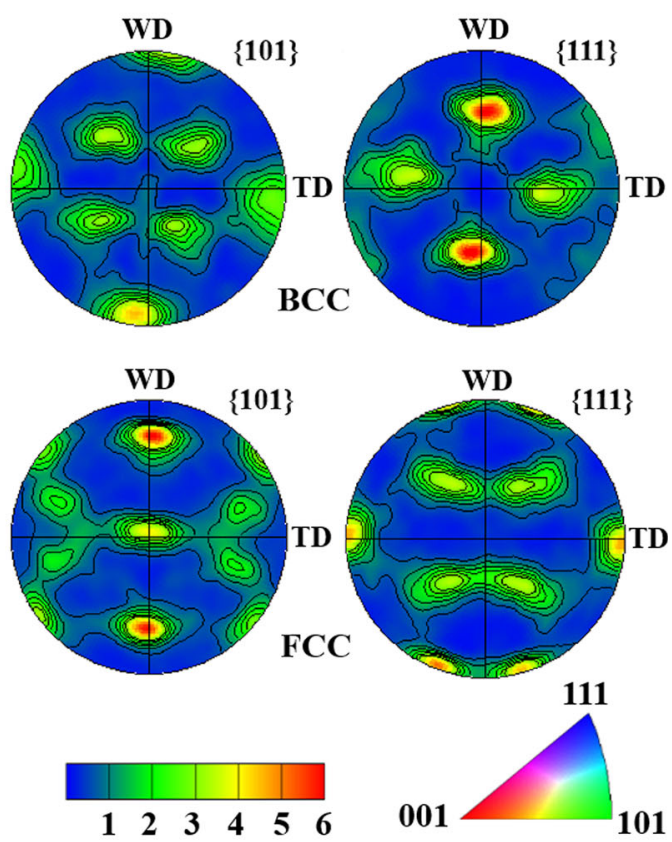

(d)

Fig. 2-Microstructural characteristics of the DSS BM, (a) OM micrograph with few highlighted austenite isles in the ferrite matrix, (b) EBSD map with IPF coloring with respect to the ND of the BM, (c) EBSD phase map showing the morphology of austenite (blue) and ferrite (red). Black and white lines, respectively, indicate the traces of high-angle grain boundaries (HAGB) with misorientation above 15 deg, and $\Sigma 3$ twin boundaries with a deviation of 5 deg. (d) $\{011\}$ and $\{111\}$ polefigures showing the initial textures in both ferrite matrix (BCC) and austenite isles (FCC) of the BM (Color figure online).

entire HAZ/TMAZ interface of S275 steel, except for the region closer to the root of the weld (see Figure 5(f)) in which the average grain size of the cluster of fine grains is observed to be smaller by at least two order of magnitudes $(\approx 2 \mu \mathrm{m})$. A transient region of approximately 2 to $3 \mathrm{~mm}$ thickness is observed in the TMAZ, between the HAZ and the SZ on the S275 steel side. This has uniform grains close to equiaxed ferrite grains, with a fine grain size of $\approx 4 \mu \mathrm{m}$ (see Figures 5(c), 6(c)). The SAZ is a region of $\approx 200 \mu \mathrm{m}$ thickness, having uniform equiaxed ferrite grains with an average grain size of 3 to $4 \mu \mathrm{m}$ which appears to be slightly smaller than that of
TMAZ (see Figure 5(c)). The microstructure in the SZ is ferritic with near-equiaxed grain morphology (see Figure 5(b)) with an average grain size of $\approx 5 \mu \mathrm{m}$ that widens from the SAZ to the root of the weld. The microstructure in the $\mathrm{SZ}$ is not uniform, as its center is dominated by grains with nearly lath morphology and globular ferrite grains along these small laths (see Figure 5(b)). The fraction of equiaxed ferrite grains increases, while moving from the center of the SZ toward the interface with the TMAZ. A transition from the SZ to a globular ferritic microstructure in the TMAZ is rather gradual in the S275 steel side which is 


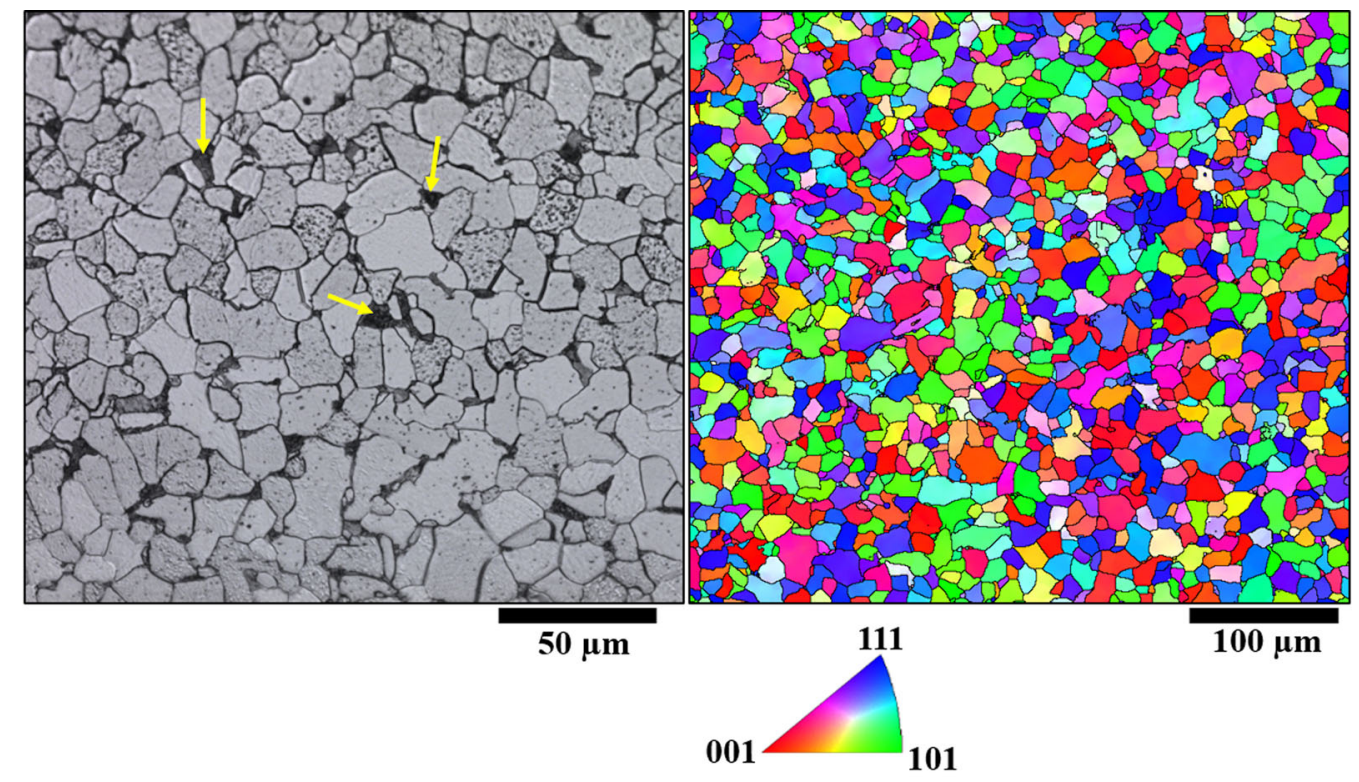

(a)

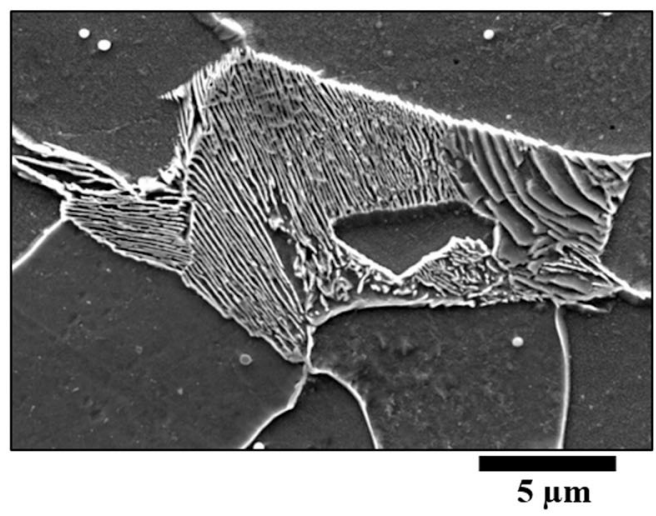

(c) (b)

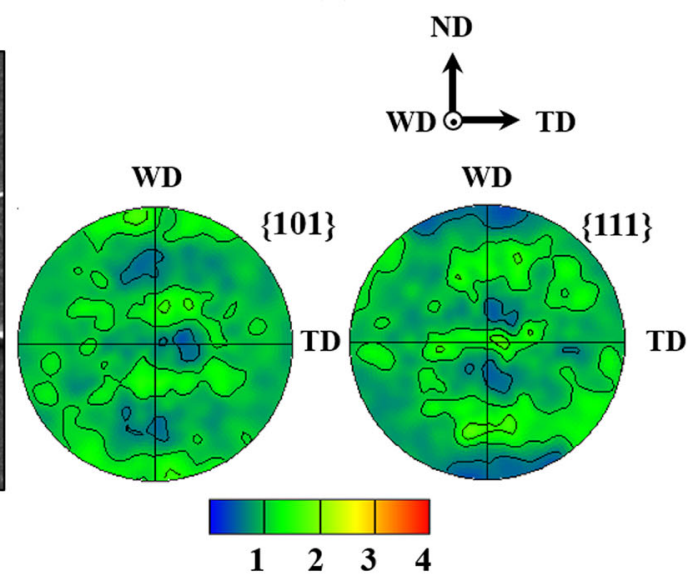

(d)

Fig. 3-Microstructural characteristics of the S275 BM, (a) OM micrograph showing the ferrite grains with arrows highlighting examples of pearlite colonies, (b) EBSD map with IPF coloring with respect to the ND of the BM, $(c)$ high resolution SEM micrograph of a typical pearlite colony at a higher magnification, and $(d)\{011\}$ and $\{111\}$ polefigures showing the initial textures in BM.

on the RS side of the weld, compared to the sharp transition from TMAZ to SZ in the DSS on AS side of the weld.

One of the interesting observations made by $\mathrm{OM}$ is that of the micro-interlocking fingers in the interface of the two dissimilar materials in the center of the weld, as seen in Figure 5(e). The grain size in the interlocking fingers increased significantly by few orders of magnitude compared to the average grain size of the immediate nearby regions in the SZ of S275, such that in some cases the entire finger is one grain (see an example highlighted by an arrow in Figure 5(e)). This can also be seen in the EBSD IPF map shown in Figure 6(b).

Figure 7 shows the plots of misorientation angle distributions of ferrite in DSS, austenite in DSS and S275 steel, for different regions of the weld. For both materials, a significant fraction of low-angle grain boundaries (LAGB) with misorientation angles $<10$ deg has been observed in the HAZ, which then tends to decrease by moving into TMAZ and drastically eased off in the center of the SZ. Both the ferrite matrix and austenite colonies in the BM of DSS have substantial fractions of LAGBs, with that of the austenite being significantly higher, while the S275 steel microstructure is almost free from LAGBs and substructures. Unlike the DSS side, the microstructure of different regions of the S275 welds cannot be easily distinguished by micrographs, while their plots of misorientation angle distributions are noticeably different (see Figure 7).

A detailed statistical analysis of the misorientation angle/axis pairs across the austenite boundaries in the BM of DSS showed that about 27 pct (Figure 7(a)) of the high-angle grain boundaries (HAGB) with misorientations above $10 \mathrm{deg}$ displayed the first order twin 


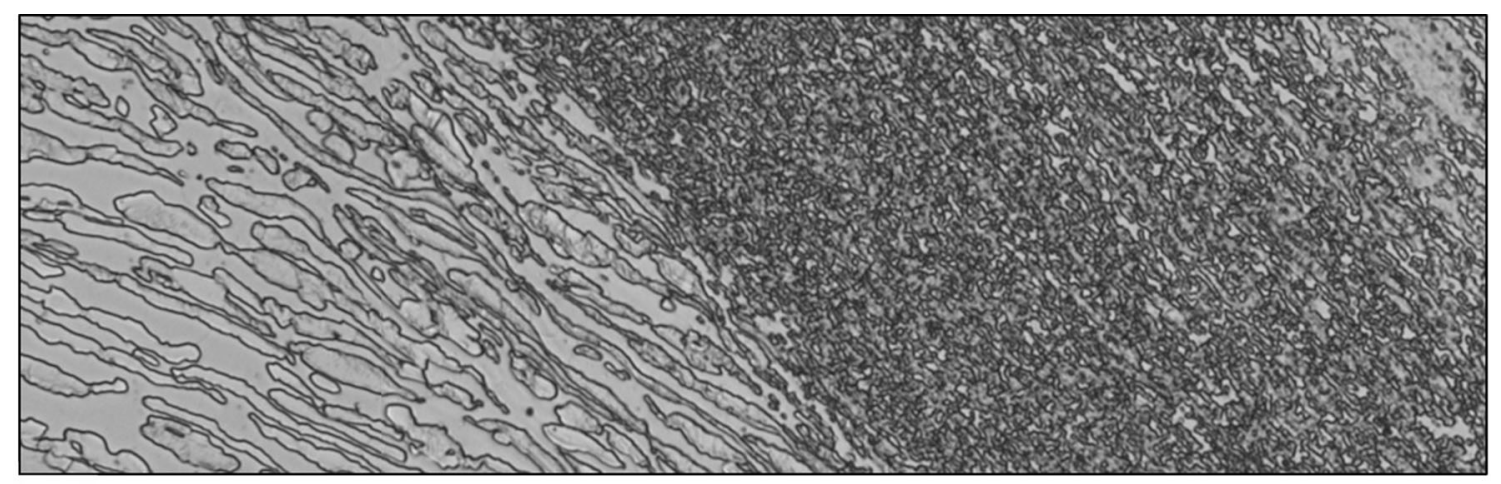

(a)

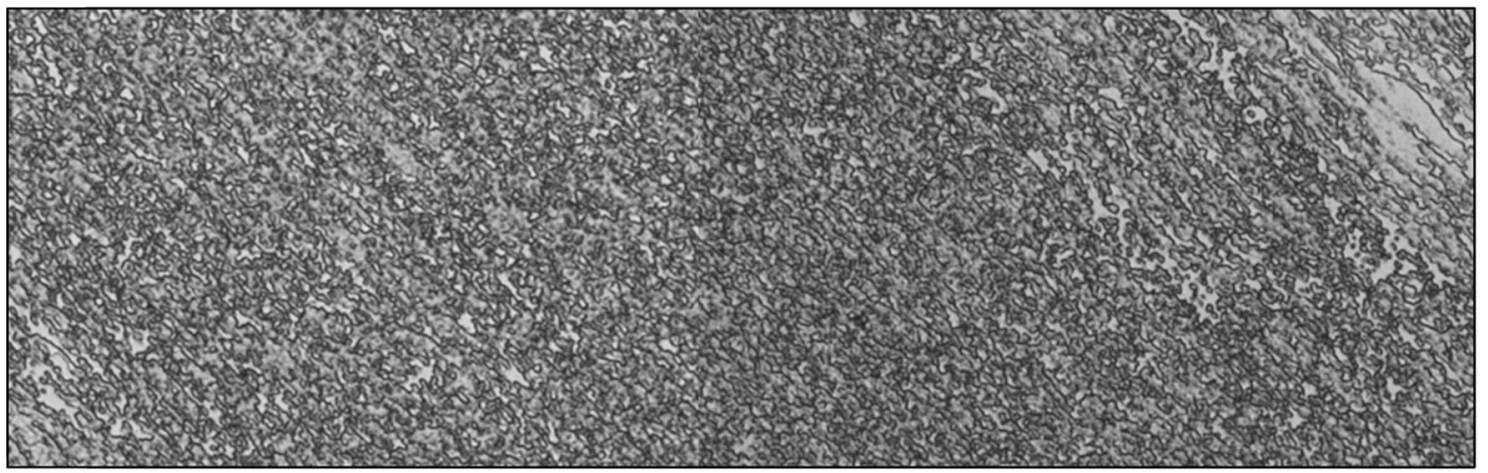

(b)

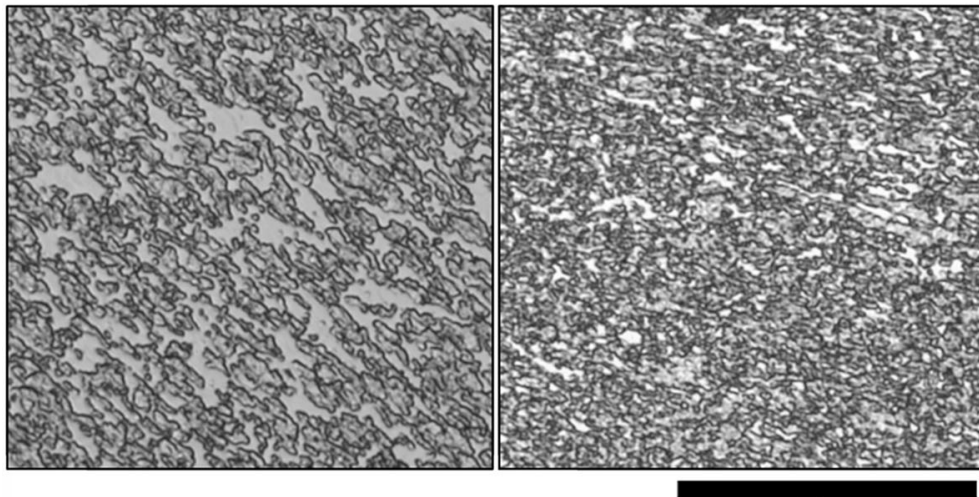

$50 \mu \mathrm{m}$

(c)

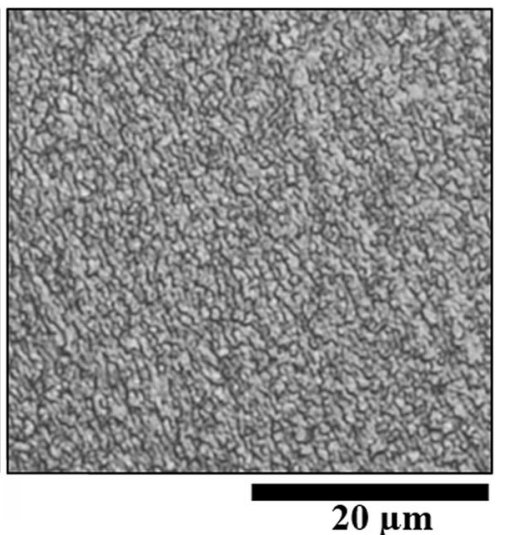

(e)

Fig. 4 - Optical micrographs of the microstructure for different regions of the weld in DSS side, (a) transition between BM, HAZ, and TMAZ, (b) transition between TMAZ and the SZ, (c) the SZ, (d) SAZ of the DSS, (e) SZ close to the root of the weld. Note that the scale of micrographs (a) through (d) are identical, and that of (e) is provided separately due to higher magnification. Locations of all micrographs are highlighted on the weld cross section shown in Fig. 1.

( $\Sigma 3)$ orientation relationship, described within the framework of coincidence site lattice (CSL) model, with a deviation of 2 deg are characterized by 60 deg rotation about $\langle 111\rangle$ axis (see Figure 7(e)). Following FSW, although the volume fraction of austenite was measured to be approximately the same as that of the BM (i.e., 36 pct), the initially sharp peak in the austenite misorientation distribution centered on the ideal $\Sigma 3$ CSL orientation relationship decreased to about 4 pct. These are highlighted by arrows in Figures 7(a) and (d). The misorientation axis vectors expressed in the crystal lattice coordinates for austenite in the SZ of the weld, displayed a rotation about $\langle 111\rangle$ direction predominantly (see Figure 7(f)) indicating that these boundaries are in fact $\Sigma 3$ CSL twins.

\section{Weld Microhardness}

Figure 8 shows the microhardness map of the weld cross section along with the plot of microhardness profiles across both materials from $\mathrm{BM}$ on AS (i.e., DSS) to BM on RS (i.e., S275 steel). The typical 


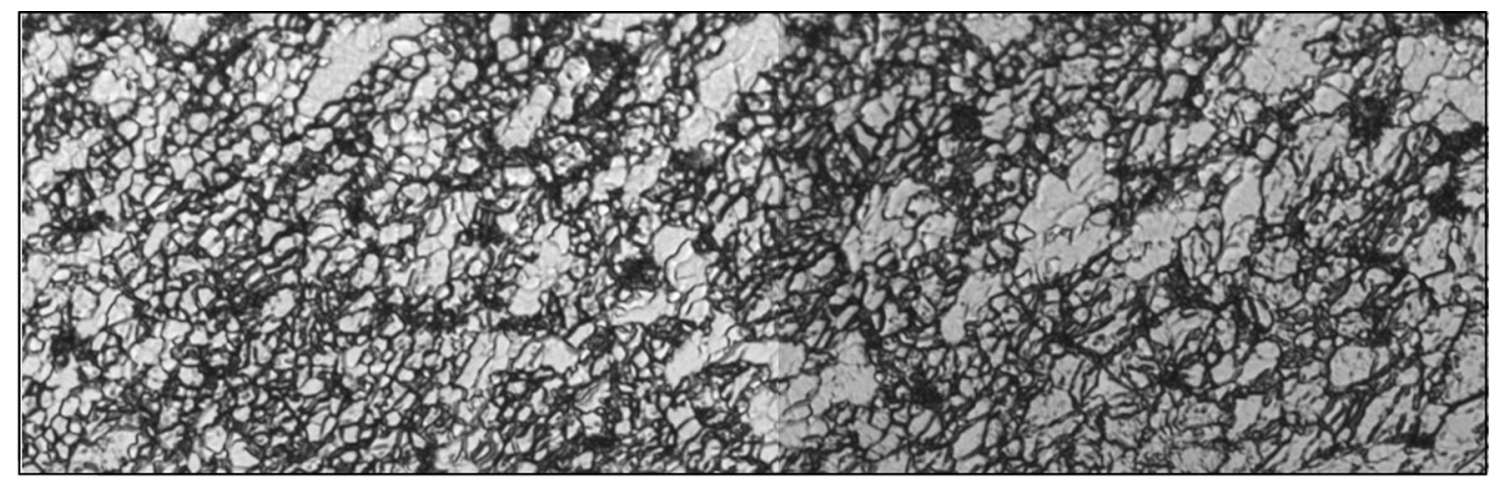

(a)

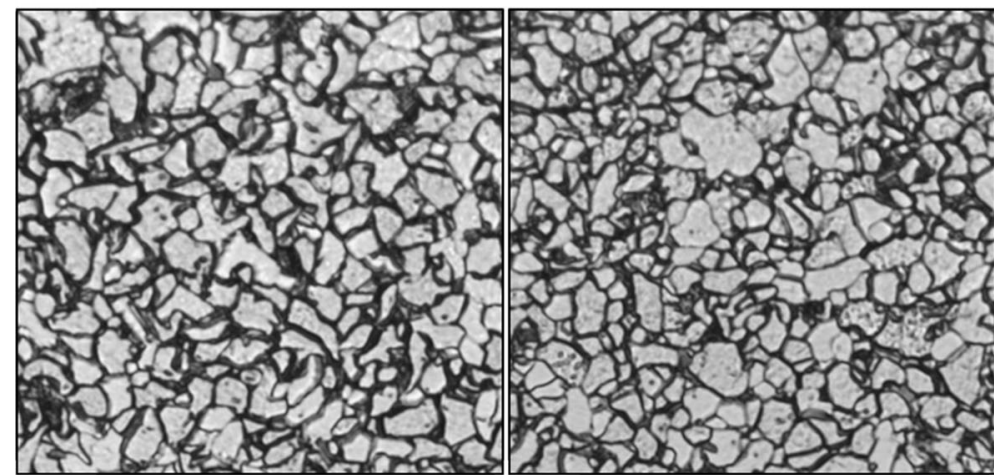

(b)

(c)

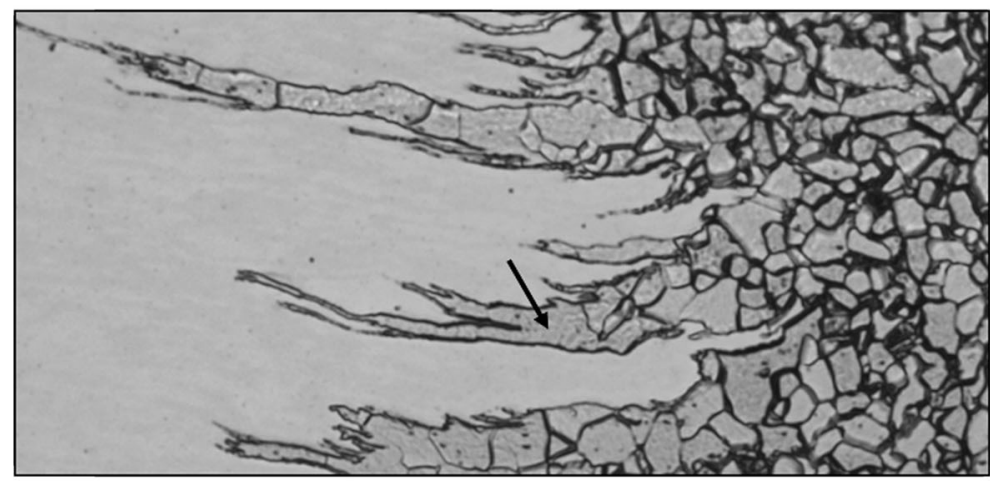

(e)

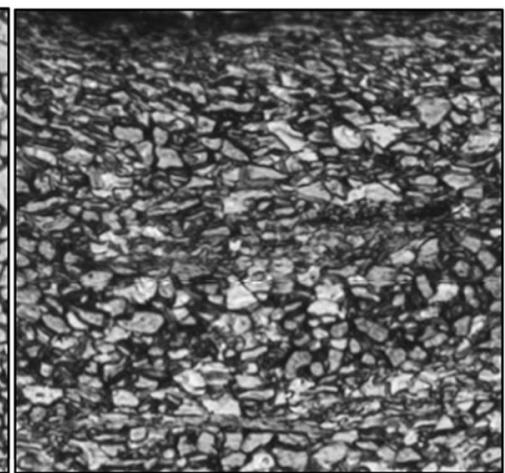

(d)

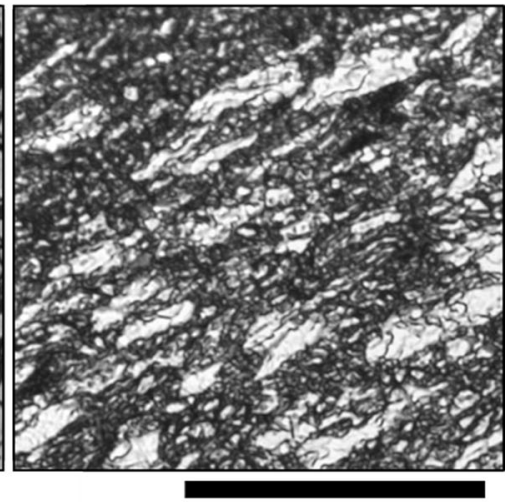

$50 \mu \mathrm{m}$

(f)

Fig. 5- Optical micrographs of the etched microstructure for different regions of the S275 steel weld, (a) transition between BM, HAZ, and TMAZ. Note that the BM is on far right and the TMAZ is on far left hand side of the micrograph. $(b)$ Center of the SZ, $(c)$ TMAZ, $(d)$ SAZ, (e) center of the SZ showing the interlocking fingers from sides of the weld, and $(f)$ transition from HAZ to TMAZ toward the root of the weld. Locations of all micrographs are highlighted on the weld cross section shown in Fig. 1.

hardness of the BM of the DSS was in the range 260 to $285 \mathrm{HV}$, while the hardness in the HAZ increased by approximately 15 to $30 \mathrm{HV}$, compared to that of the $\mathrm{BM}$. In the regions of the TMAZ and the SZ of DSS which displayed a significantly smaller ferrite/austenite grain size, the hardness increased to $\approx 320$ to $340 \mathrm{HV}$ and remained almost unchanged up to the interface with the $\mathbf{S} 275$ steel in the middle of the weld. The measured hardness of the SAZ of DSS is slightly higher $(\approx 380$ HV) than those measured in TMAZ and the SZ. The maximum measured hardness in the DSS side was that measured for the root of the weld, which exceeds 560 HV on the bottom edge (Figure 8(a)). Due to the significant difference between the level of hardness of DSS and S275 steel, the variation in hardness distribution in the S275 steel side is not obvious in Figure 8(a). Hence, for the purpose of a clear illustration of the hardness distribution in the S275 steel side of the weld, the data for DSS has been excluded from the hardness map and shown with a modified scale in Figure 8(b). It 


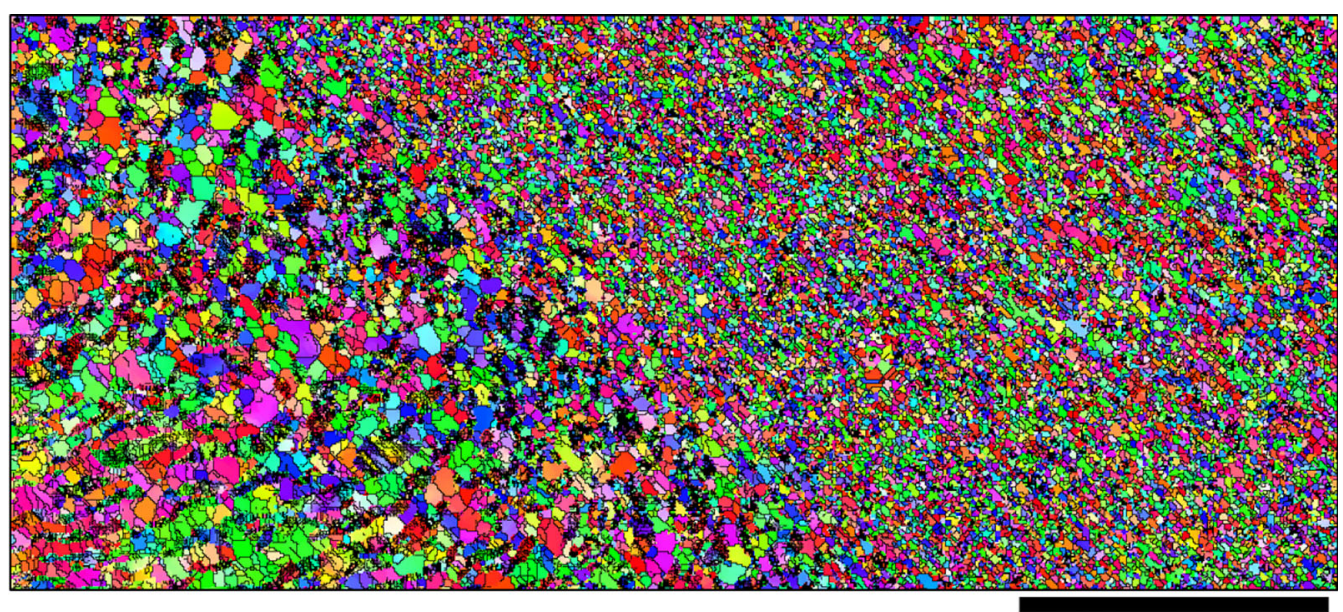

(a)

$100 \mu \mathrm{m}$

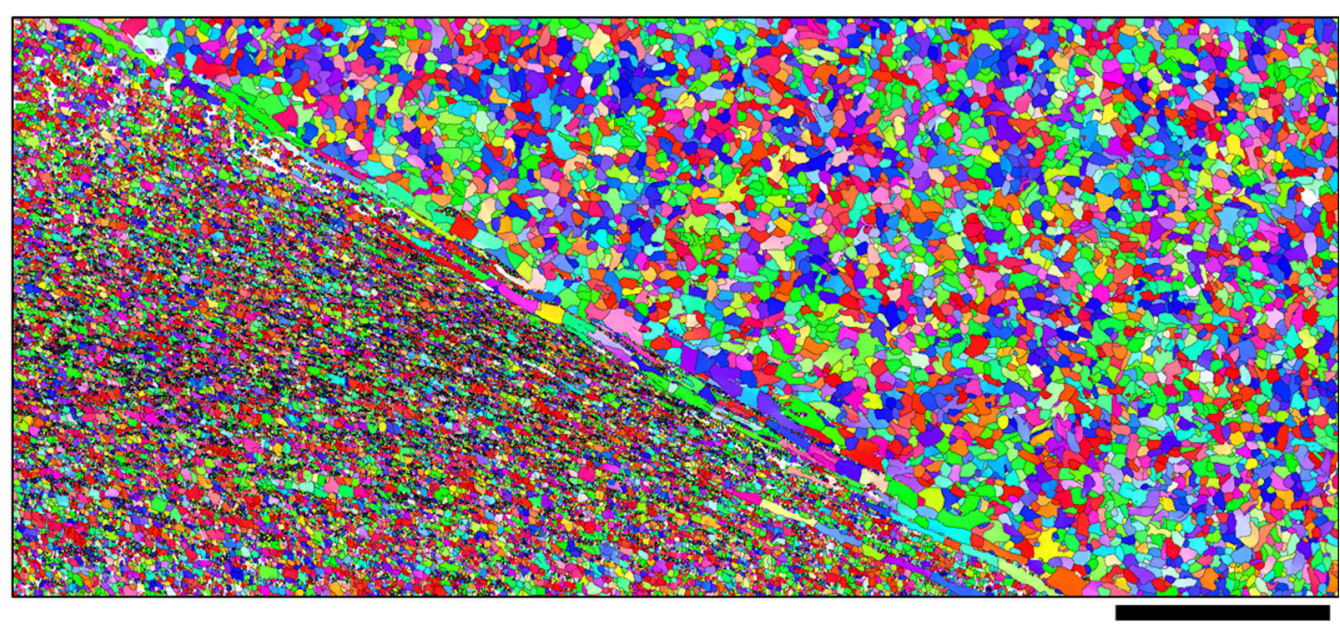

(b)

$100 \mu \mathrm{m}$

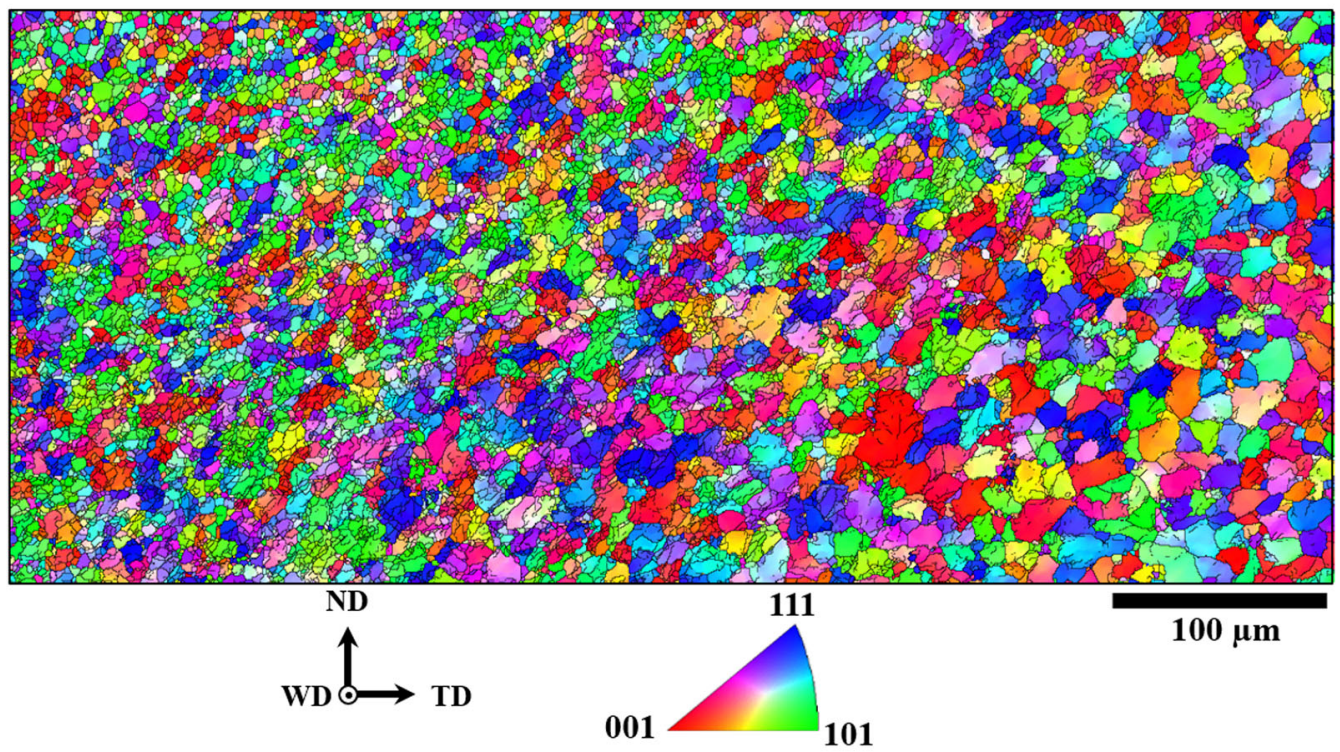

(c)

Fig. 6-High-resolution EBSD IPF coloring maps with respect to the ND of $(a)$ a region between HAZ and TMAZ of the DSS on AS, (b) the interface of DSS and S275 steel in the center of SZ, $(c)$ a region between TMAZ (far left), HAZ, and BM (far right) of the S275 steel on RS. See Fig. 1 for the positions of EBSD maps. 


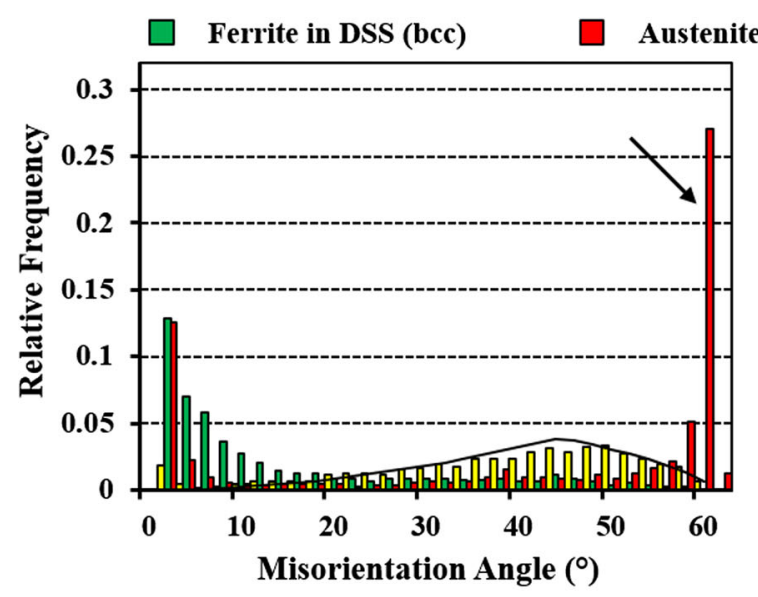

(a)

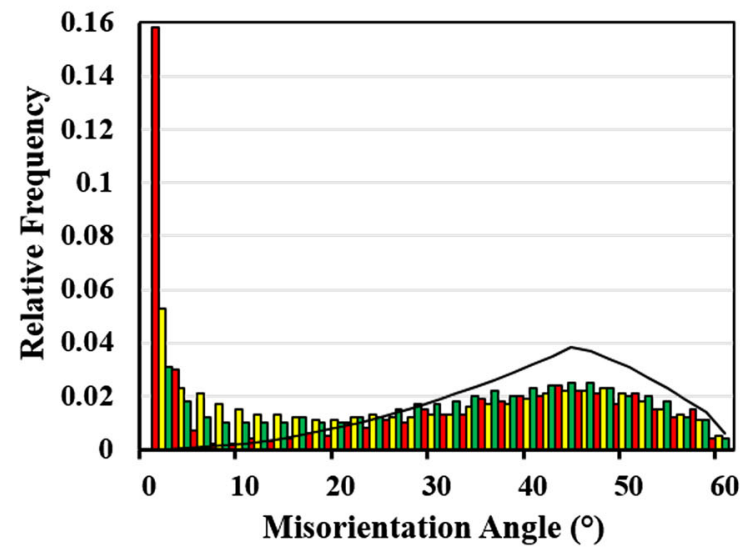

(c)

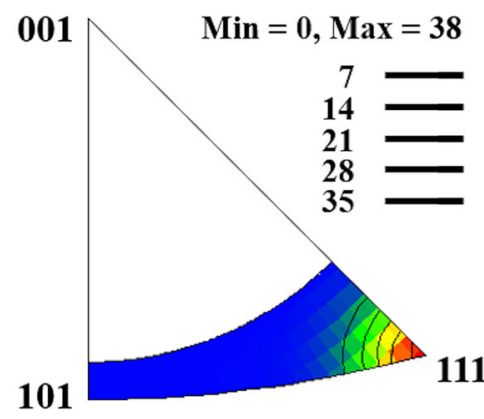

(e)

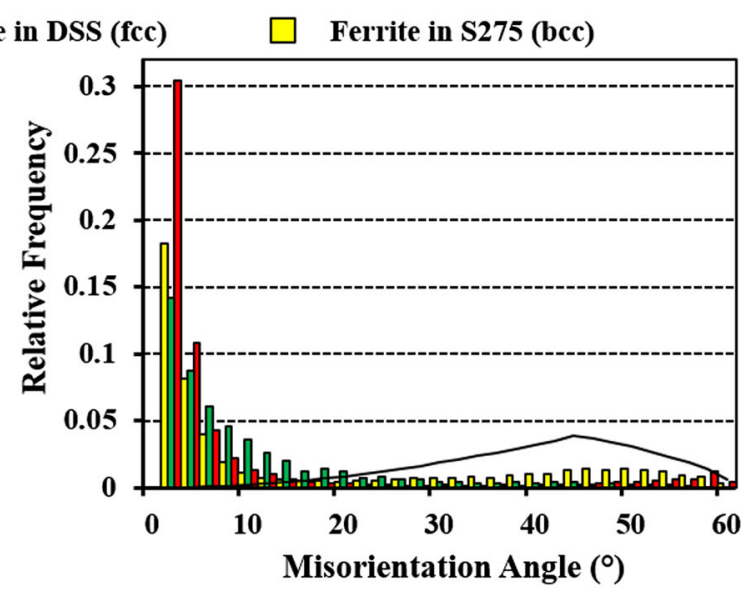

(b)

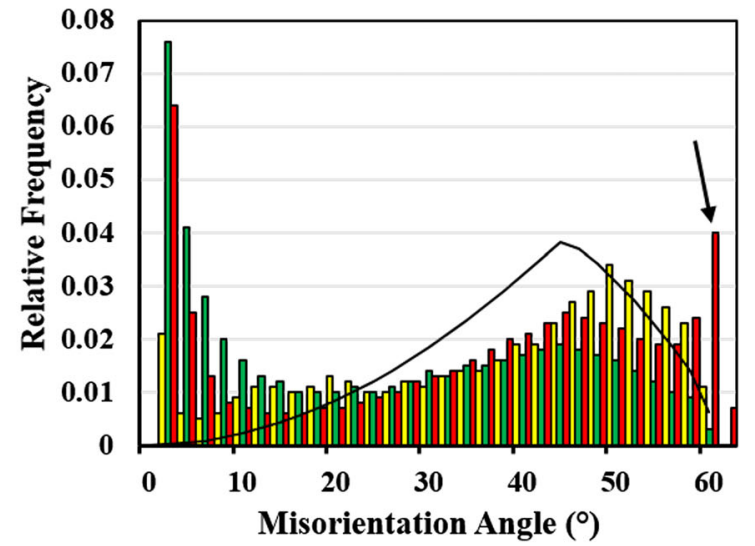

(d)

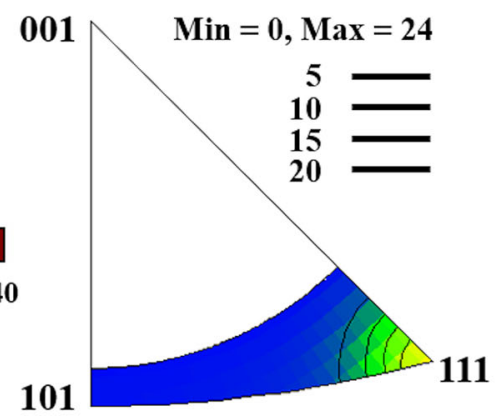

(f)

Fig. 7-Misorientation angle distributions of the ferrite and the austenite phases with bcc and fcc crystal structures in the DSS side of the weld, and those of the ferrite phase with bcc crystal structure in the S275 side of the weld, $(a)$ the BM, $(b)$ HAZ, $(c)$ TMAZ, and $(d)$ center of SZ. Note that the scale of the vertical axes of all plots are not the same, for clarity. $(e)$ and $(f)$ respectively show the distribution of misorientation axis vectors in the crystal lattice coordinates for the BM and center of SZ, corresponding to the plots for austenite phase in DSS presented in (a) and (d).

can be seen that the hardness of the BM of the S275 steel ranged from $\approx 140$ to $155 \mathrm{HV}$. This is then increased to $\approx 165 \mathrm{HV}$ approaching the weld in the HAZ. The average hardness in TMAZ and the SZ of S275 steel is about $\approx 175 \mathrm{HV}$ and remains almost unchanged throughout these regions. The maximum hardness in S275 side is measured at the root of the weld, similarly to the DSS side, and at the SAZ where it approached $200 \mathrm{HV}$.

\section{Weld Microtexture}

Figure 9 shows the OIM using IPF coloring with respect to the ND and phase map, across the DSS on AS in the probe dominated area, starting from the BM to the center of the SZ. Their corresponding $\{101\}$ and $\{111\}$ polefigures of $600 \mu \mathrm{m}$ wide segments are provided for the ferrite matrix and austenite isles, respectively. The microstructure of the BM percolates into the HAZ 


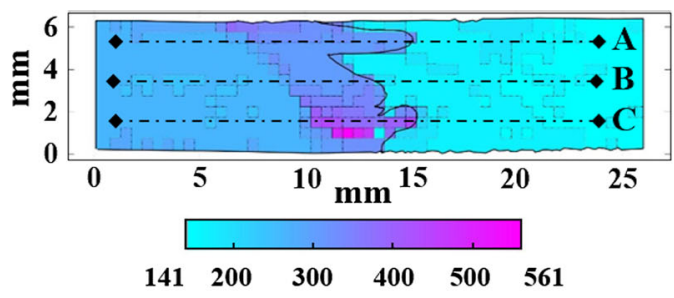

(a)

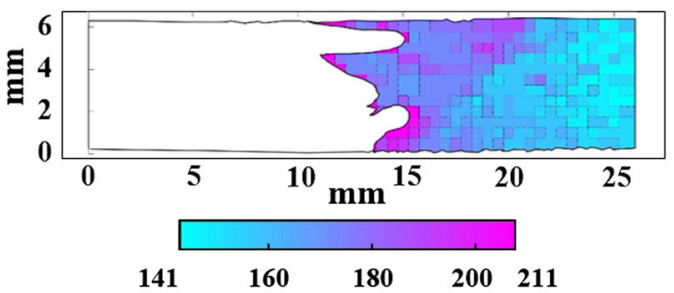

(b)

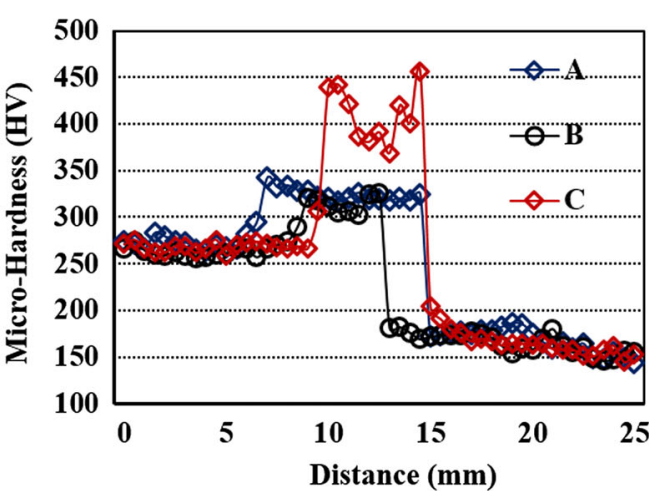

(c)

Fig. 8- (a) Microhardness map of the dissimilar weld cross section including the BM, HAZ, TMAZ, and SZ of both materials, (b) microhardness map of the S275 steel side of the weld cross section at a different scale, and $(c)$ profiles of the microhardness along the lines shown in (a).

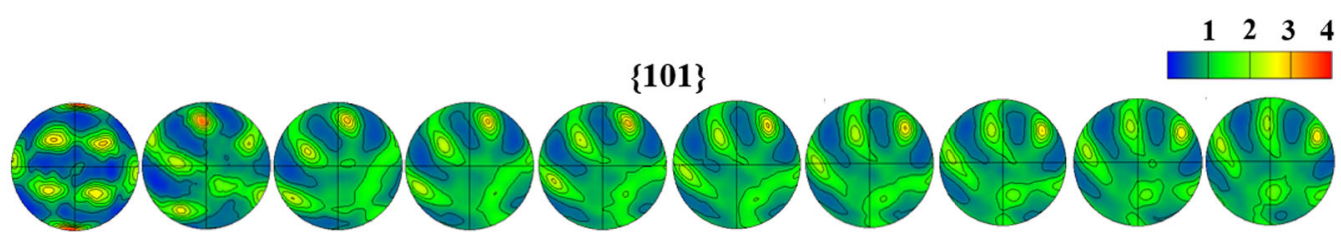

(a)

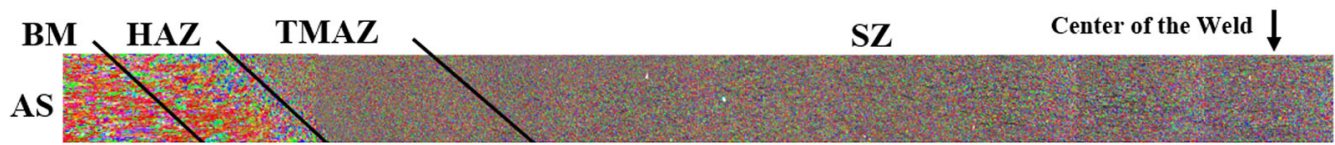

(b)

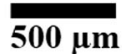

$\{111\}$

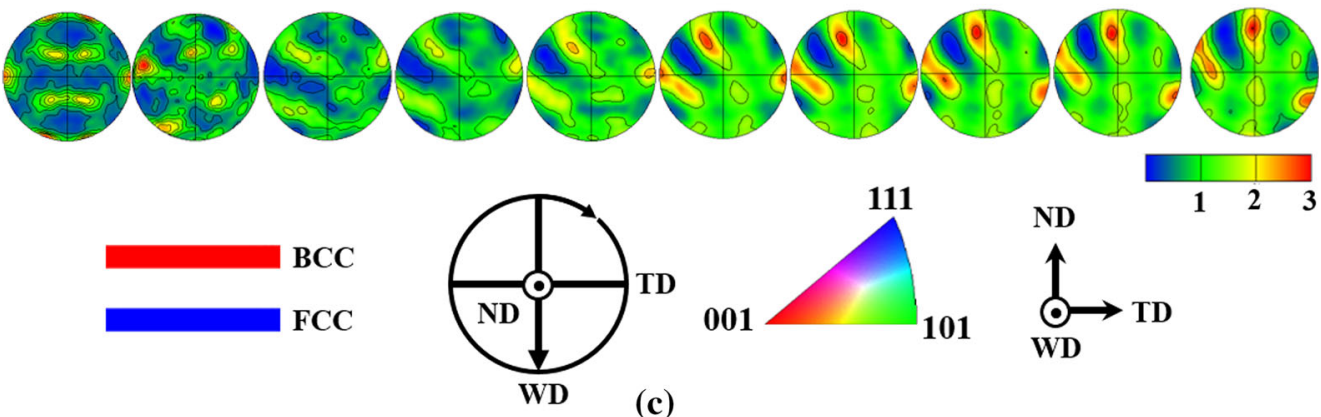

(c)

Fig. 9-EBSD maps across the BM, HAZ, TMAZ, and SZ of the DSS on AS of the weld, with their associated polefigures in $600 \mu \mathrm{m}$ steps along the whole map, (a) (101) polefigures of ferrite with bcc crystal structure in DSS, (b) EBSD IPF coloring with respect to the ND and phase maps, and (c) (111) polefigures of austenite with fcc crystal structure in DSS. The position of the map is indicated in Fig. 1. For all the polefigures the ND is in the center and the WD at the bottom.

of the weld where the relatively strong texture of both ferrite and austenite phases in the as-received material (see Figure 2(d)) becomes weaker and starts to transform to a completely different texture distribution by rotation $(\approx 20$ to $30 \mathrm{deg})$ around ND and TD. The rotation of the grains that are either clockwise $(\mathrm{CW})$ or counter-clockwise $(\mathrm{CCW})$ can be seen in the EBSD maps in Figure 9(b), and also in the OM micrographs 
presented in Figure 4(a). The texture is then transformed into an entirely different texture distribution than that of the BM after moving into the TMAZ, with uniform equiaxed fine ferrite and austenite grains. From the TMAZ to the center of the SZ, for both ferrite and austenite phases, the textures are similar, but with slightly different intensities and a measurable systematic rotation. The OIM map in Figure 9(b) shows no dominant orientation in the TMAZ and SZ, with no alternating texture. Despite changes in the morphology, size and distribution of austenite colonies across the TMAZ and the SZ (Figure 9(b)), the phase map shows that the fraction of ferrite and austenite do not change significantly from those of the BM (i.e., 64 pct and 36 pct respectively).

At the extreme AS side of the weld (i.e., TMAZ of DSS), the strong (101) pole of the ferrite texture lies in the TD plane, tilted $\approx 70 \mathrm{deg}$ from the ND (see Figure 9(a)). This then rotates around the ND as a function of distance, $x$, from the center of the weld, such that at the center, where $x=0$ the stronger (101) pole is at an angle of $\approx 25 \mathrm{deg}$ from the WD plane, with a slightly increased tilted angle (i.e., from $\approx 70 \mathrm{deg}$ to $\approx 80$ $\mathrm{deg}$ ) from the ND. The strong (111) pole of the austenite texture at the extreme AS side lies on a plane at $\approx 35 \mathrm{deg}$ from the WD plane, tilted $\approx 55 \mathrm{deg}$ from the ND (see Figure 9(c)). In a similar manner to the ferrite texture, the austenite polefigure rotates around the ND as a function of distance from the center of weld, such that at the center, the strong (111) pole lies in the TD plane, with a slightly increased tilted angle (i.e., $\approx 65 \mathrm{deg}$ ) from the ND. It is interesting to note that the austenite's (111) polefigure becomes significantly stronger by moving from TMAZ into the SZ, where the texture intensity remains to the center of the weld. Overall, both ferrite and austenite textures in the DSS have $\approx 60 \mathrm{deg}$ systematic $\mathrm{CW}$ rotation around the ND from the extreme AS side to the center of the weld.

A similar evolution can be observed from the center of the weld to the extreme RS side (i.e., S275 steel), with the only difference being that the transition from SZ to TMAZ is much broader in the AS than the RS. Figure 10 shows the OIM using IPF coloring with regard to the ND, across the $\mathrm{S} 275$ steel on $\mathrm{RS}$ in the probe dominated area, starting from the $\mathrm{BM}$ to the center of the SZ. Their corresponding $\{101\}$ polefigures of $600 \mu \mathrm{m}$ wide segments are also provided. The microstructure of the BM extends into the HAZ where the randomly distributed texture of the BM (shown also in Figure $3(\mathrm{~d})$ ) rotates a few degrees $(\approx 5 \mathrm{deg}) \mathrm{CW}$ around the ND. The random texture then transforms into an off axis shear texture by stepping into the TMAZ, with uniform equiaxed ferrite grains. From the TMAZ toward the interface with the SZ, the transformed texture becomes stronger; thereafter to the center of the SZ the textures are similar with a systematic rotation as a function of distance from the center of the weld. The OIM in Figure 10 shows dominant near $\langle 001\rangle$ (Red) and $\langle 111\rangle$ (Blue) grain orientations in a region of $\sim 2.5 \mathrm{~mm}$ thickness in TMAZ on the far RS of the SZ. Beyond this region to the center of the SZ, it is clear that the near $\langle 101\rangle$ (green) grain orientation becomes dominant. This has been reflected in the polefigures by the stronger intensity of the poles in the SZ where the near $\langle 101\rangle$ grain orientation is dominant. At the center of the weld, which is about $1.2 \mathrm{~mm}$ away from the interface with the DSS, at this particular location, the strong (101) pole is in the TD plane, tilted $\approx 60 \mathrm{deg}$ from the ND. Note that this makes the pole at an angle of $\approx 150 \mathrm{deg}$ from the WD. This then rotates around the ND as a function of distance from the center of the weld, $x$, (i.e., $\mathrm{CCW}$ rotation toward the interface with DSS, and CW rotation toward the extreme $\mathrm{RS}$ ), keeping the $\approx 60$ deg tilted angle from the ND. The maximum rotation at the extreme RS side (i.e., TMAZ) is about $\approx 55 \mathrm{deg}$ from the center of the weld, around the ND.

\section{E. Weld Residual Stress}

Figures 11(a) and (b) show residual stress maps assessed from the weld cross section along the weld's TD and along the weld ND, respectively. The outline of the weld and the interface between the two materials are highlighted for clarity. The magnitudes and distributions of the measured residual stress components varies for different regions of the weld. The associated uncertainties for these measurements were all within $\pm 30 \mathrm{MPa}$ considering 95 pet confidence interval. In both sides of the weld, the transverse residual stress is compressive in the SAZ (Figure 11(a)), with the maximum stress of $327 \pm 30 \mathrm{MPa}$ in the DSS and $-176 \pm 30 \mathrm{MPa}$ in the $\mathrm{S} 275$ steel. This shows that the magnitude of the compressive residual stress in the SAZ of DSS is significantly larger, by almost an order of magnitude, than that of the SAZ of S275 steel. The measured residual stress in the SZ of DSS is compressive with significantly lower magnitudes, and that of the SZ of $\mathrm{S} 275$ steel is negligible with magnitudes around $0 \mathrm{MPa}$. In the BMs the measured stresses are both tensile, with that of the DSS larger, with magnitudes approaching $150 \mathrm{MPa}$. It appears that the tensile transverse residual stress is balanced by compressive stresses on both edges of the plate, one of them being SAZ, with different magnitudes depending on the material. Overall, the SZ and TMAZ of both materials in the welded region have very small residual stress magnitudes.

Figure 11(b) shows that the normal residual stress is almost entirely compressive in the S275 steel side of the weld with a maximum stress of $-150 \mathrm{MPa}$, and conversely tensile in the DSS side, with a maximum measured stress of $+342 \mathrm{MPa}$ in the BM. The measured residual stress map in the ND appears to be distributed in a manner that intends to twist the weld.

\section{DISCUSSION}

\section{A. Microstructure Evolution}

The low magnification OM of the etched weld cross section (see Figure 1 for S275 steel) showed that the welded region can be identified from the BM; however, different zones of the weld (e.g., SAZ or TMAZ) cannot 


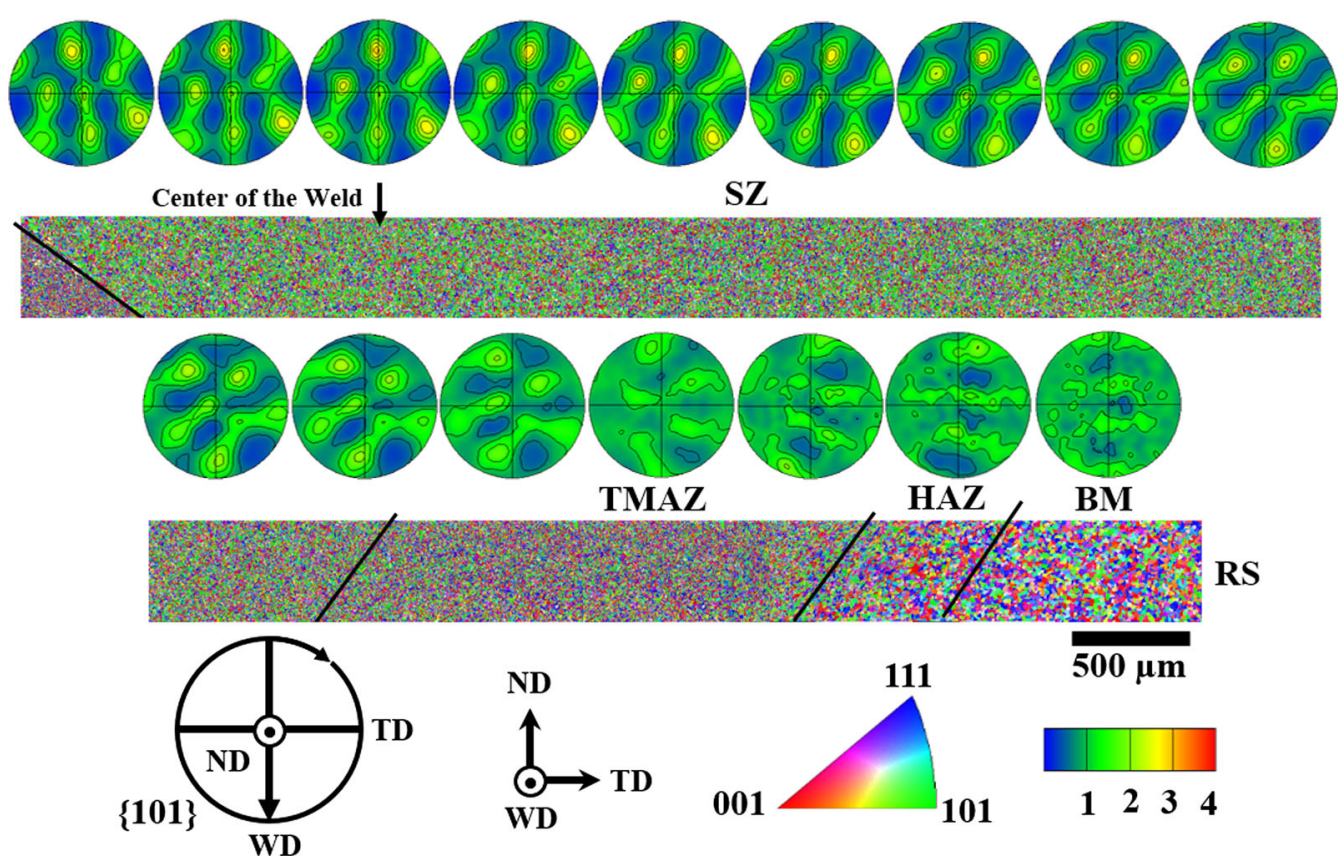

Fig. 10 - EBSD IPF coloring maps with respect to the ND across the BM, HAZ, TMAZ, and SZ of the S275 steel on RS of the weld, with their associated (101) polefigures in $600 \mu \mathrm{m}$ steps along the whole map. The positions of the map is indicated in Fig. 1. For all the polefigures the ND is in the center and the WD at the bottom. The two rows of OIMs and polefigures are the extensions of one another and need to be looked into as a single row.

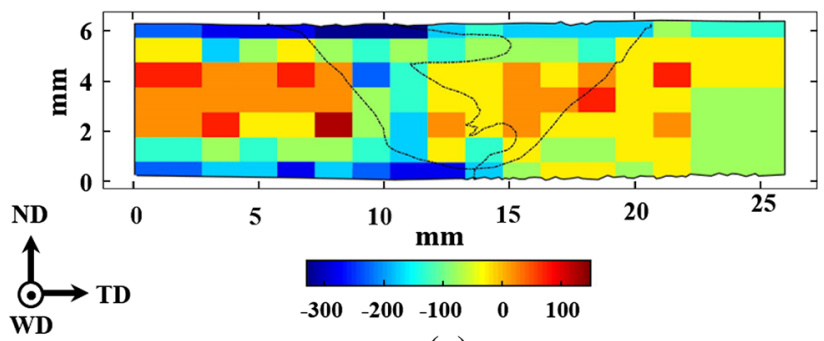

(a)

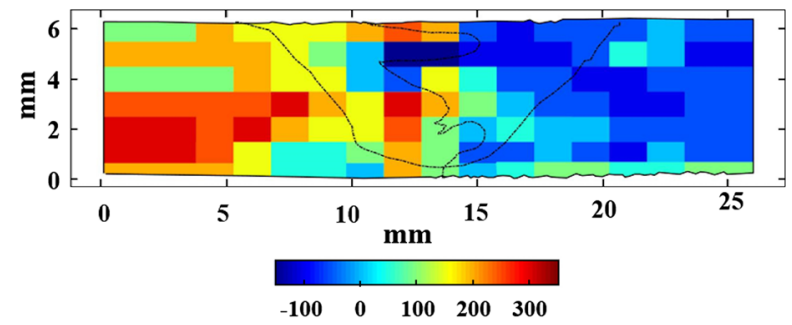

(b)

Fig. 11-Residual stress distribution, measured by XRD, on the dissimilar materials' weld cross section, $(a)$ along the TD and $(b)$ along the ND. The interfaces of the weld with the parent materials are highlighted in both maps.

be distinguished at low magnifications. It is apparent that the weld interior exhibits a high degree of continuity, although few features are observed toward the root of the weld on DSS side that appeared to be defects (Figure 1). The presence of wormholes on the AS of the welded joint may be caused by a lack of flow due to low heat input during the FSW process. ${ }^{[60,61]}$ A significant grain growth is observed in the interlocking fingers where the two dissimilar materials join in the interface in the center of the weld (see Figures 5(e) and 6(b)). A previous study on dissimilar FSW between the same materials as those used in this study showed excellent chemical bonding between the dissimilar materials with chromium, nickel and molybdenum measured to diffuse across the interface from the DSS to the S275 steel. ${ }^{[46]}$ Hence, due to the higher possibility of carbon diffusing more readily than chromium and nickel, the significant ferrite grain growth on the interface (see Figure 5(e)) could be a result of decarburization in S275 steel on the boundary. ${ }^{[62]}$

The area fraction of the S275 steel appears to be larger than that of the DSS such that in the middle of the weld in the probe dominated area, the distance from the center of the weld to the boundary between HAZ and TMAZ on the RS $(\approx 6.9 \mathrm{~mm})$ is $\approx 1.5 \mathrm{~mm}$ longer than that of the AS $(\approx 5.4 \mathrm{~mm})$. This can be seen by comparing the lengths of the long EBSD maps for both DSS and S275 steel presented in Figures 9 and 10, respectively. The result of previous research on dissimilar FSW steels showed that placing the stronger steel on the AS increased the amount of martensite formation and reduced the size of SZ compared to a condition where the stronger steel is on the RS. ${ }^{[63]}$ This was due to the higher temperature and stress resulting from placing the harder steel on the AS. High magnification OM of both materials in the weld region reveals variations in the microstructure and grain morphology in different zones (see Figures 4 and 5). The interface between the SZ and TMAZ is very distinct on the DSS side which is located on AS, while it is more diffuse on the S275 steel 
side on the RS. The effective tapering angle of the weld varies between $45 \mathrm{deg}$ and $60 \mathrm{deg}$, depending on the distance from the SAZ, due to the geometry of the tool.

Temperature measurements were not carried out during the FSW neither in the part nor in the tool shoulder, and hence, the exact temperatures of different regions of the weld can only be estimated through the observations made on the resulted microstructures. Since the microstructure in the SZ of the S275 steel contains a mixture of acicular ferrite and granular ferrite (see Figure 5(b)), it can be postulated that during FSW the temperature of the ferritic-pearlitic microstructure of the BM (Figure 3) on the RS exceeded the $\mathrm{Ac}_{1}$ temperature. However, the mixed acicular ferrite and granular ferrite microstructure, with the dominance of the latter, implies that the temperature did not exceed the $\mathrm{Ac}_{3}$ temperature, but was rather closer to the $\mathrm{Ac}_{1}$ temperature thereby allowing full transformation to austenite. The $\mathrm{Ac}_{1}$ and $\mathrm{Ac}_{3}$ temperatures of the grade of S275 steel used in this study, with chemical compositions listed in Table I, have been calculated to be $1079 \pm 24 \mathrm{~K}(806 \pm$ $\left.24{ }^{\circ} \mathrm{C}\right)$ and $1168 \pm 35 \mathrm{~K}\left(895 \pm 20^{\circ} \mathrm{C}\right)$, respectively, considering a $20 \mathrm{~K} / \mathrm{s}\left(20{ }^{\circ} \mathrm{C} / \mathrm{s}\right)$ heating rate in the analyses. Changing the heating rate by $10 \mathrm{~K} / \mathrm{s}\left(10^{\circ} \mathrm{C} / \mathrm{s}\right)$ (i.e., slower or faster) in the analysis results in less than $15 \mathrm{~K}\left(15^{\circ} \mathrm{C}\right)$ variation from the average values. ${ }^{[64]}$ This shows that although the temperature on the AS may rise to temperatures slightly higher than that of the RS due to firstly, the harder nature of the DSS, ${ }^{[63]}$ and secondly the higher heat input resulted from the alignment of both rotational and translational movements of the probe in a same direction, ${ }^{[40-44]}$ the temperature cannot still be far above the $\mathrm{Ac}_{1}$ of the S275 steel (i.e., $1079 \pm$ $24 \mathrm{~K}$ ) during FSW, considering a fairly high thermal conductivity of steels.

Owing to their chemical compositions, on heating, duplex stainless steels transform entirely to ferrite at temperatures about 1300 to $1400{ }^{\circ} \mathrm{C}$, and maintain this microstructure at temperatures up to their melting point. For lower temperatures, around that of the $\mathrm{Ac}_{1}$ for the S275 steel (i.e., $1079 \pm 24 \mathrm{~K}$ ), given the fast nature of the FSW process, the two-phase microstructure of DSS is maintained with a negligible decrease in the fraction of austenite and minimal grain growth. ${ }^{[65-68]}$ At this temperature, the DSS is subjected to extremely high level of shear deformation, resulting in the formation of fine and ultrafine grains in the SZ, SAZ, and TMAZ (see Figure 4). However, the microstructure within these zones varies, depending on the temperature distribution from the center of the SZ toward TMAZ. In the SZ, where the temperature is higher, the austenite colonies tend to grow by a small amount (see Figure 4(c)) compared to those in the SAZ and the TMAZ (see Figures 4(b) and (d), respectively).

The heating cycle generated by the FSW, partially transforms the original ferritic-pearlitic BM microstructure of the SZ of S275 steel to austenite-ferrite dual-phase state at temperatures just above the $\mathrm{Ac}_{1}$ $(1079 \pm 24 \mathrm{~K})$. The small fraction of acicular ferrite in the microstructure of the SZ (see Figure 5(b)) indicates that the fraction of ferrite-transformed austenite must have been quite small. These mixed phases were then subjected to severe plastic deformation by the FSW, whereby the austenite phase underwent a solid-state phase transformation to acicular ferrite under conditions of rapid cooling and high shear strain..$^{[1,69,70]}$ The microstructure formed in the SZ varies, depending on the temperature distribution from the center of the SZ toward TMAZ, as the fraction of acicular ferrite completely disappeared away from the center of the SZ and by approaching TMAZ and the SAZ from all directions (Figure 5).

It is well established that during hot deformation of DSS, strain tends to preferentially partition into comparatively softer ferrite, ${ }^{[71-76]}$ in particular in the regions adjacent to the austenite/ferrite interphase, where most of the strain would be accommodated. A ratio of five has been reported for the strain accumulated in ferrite to that of austenite in DSS ${ }^{[73]}$ These strain incompatibilities in the interphase regions together with the differences in the morphology of both phases, result in the formation of complex austenite and ferrite microstructures within DSS. ${ }^{\text {77] }}$ It is widely accepted that ferrite, owing to its relatively high stacking fault energy (SFE), softens during hot deformation through an intense dynamic recovery (DRV) mechanism. ${ }^{[77]}$ Upon reaching higher levels of strain, this mechanism might evolve into "extended" DRV, which is commonly known as continuous dynamic recrystallization (CDRX).${ }^{[77]} \mathrm{CDRX}$ is not associated with the formation of new grains through nucleation and growth; it is rather the progressive conversion of low-angle grain boundaries (LAGBs), during severe plastic deformation to high-angle grain boundaries (HAGBs) upon reaching a critical misorientation angle, through continuous absorption of dislocations. ${ }^{[78-80]}$ The LAGBs are formed within the grains by DRV at the early stages of deformation. This mechanism has been observed to occur in both single-phase ferrite steel[ ${ }^{[77,81-89]}$ and ferrite in dual-phase steels. ${ }^{[81,90-95]}$ Accordingly, it can be deduced that the formation of fine and ultrafine grains in S275 steel and ferrite phase in DSS may be due to the CDRX caused by substantial levels of shear deformation and the heat induced by the FSW process.

For the S275 steel, this view can be supported by the plots of misorientation angle distributions for different zones, shown in Figure 7. In the SZ, where both the shear strain and temperature are the highest, the CDRX process progressed to a stage that has resulted in higher fraction of recrystallized grains manifested by a reasonable fit between misorientation angle distribution and the theoretical MacKenzie distribution (Figure 7(d)). The fraction of LAGBs and substructures in the misorientation angle distribution of the SZ (Figure 7(d)) may be due to the transformation-induced lattice distortion caused by small fraction of acicular ferrite formed as a result of austenite-to-ferrite transformation on cooling. In the TMAZ (Figure 7(c)), where the temperature is rather lower than the SZ, the CDRX process has not been completed, and as a result, a substantial amount of lattice strain is still locked in the microstructure. This can be seen from the high resolution EBSD map of the HAZ + TMAZ of the S275 steel in Figure 6(c), and also optical micrographs presented in 
Figures 5(a) and (f). In the HAZ, both the shear strain and temperature, induced by the FSW, were not high enough to trigger the CDRX process, and the strain has consequently left in the microstructure in form of lattice strains which has resulted in a significantly large fraction of LAGBs (Figure 7(b)). Considering the ferrite phase in the DSS, although the CDRX may be the dominant recrystallization mechanism, ${ }^{[96]}$ deducing it from the plots of misorientation angle distribution (Figure 7) is rather complicated. Due to the preferential partitioning of strain into the ferrite phase in the DSS, the grains newly recrystallized through the CDRX process can be strained again during the FSW. This can be seen in the misorientation angle distribution plots of the SZ and TMAZ of the ferrite phase (see Figures 7(c) and (d)) in which substantial fractions of LAGBs exist.

On the other hand, it is also well accepted that the austenite phase having a relatively low SFE, softens during hot deformation through discontinuous dynamic recrystallization (DDRX) that impedes the DRV process, unlike the ferrite phase. ${ }^{[77,97,98]}$ DDRX is the nucleation and subsequent growth of new grains, and the evolution of this process during hot plastic deformation gives rise to gradual softening of austenite. In single-phase austenite, DDRX grains tend to nucleate through strain-induced boundary migration which includes bulging of the original grain boundaries, which is often accompanied by multiple twinning. ${ }^{[77,99-102]}$ However, in the duplex austenite/ferrite microstructure, the population of original austenite/austenite grain boundaries that are providing potential sites for DDRX nucleation, can be significantly reduced compared to that of a single-phase austenite, resulting in delayed or suppressed DDRX in austenite. $^{[81,95]}$ The frequency of occurrence of austenite/ferrite and austenite/austenite grain boundaries in DSS is governed by the ratio and topology of the constituent phases. Results of a recent study suggest that DDRX grains are associated with HAGBs, which mainly originated from the distorted pre-existing coherent twin grain boundaries, formed at highly stressed locations in the vicinity of an austenite/ferrite interphase. ${ }^{[03]}$ This view was attributed to the low strain level partitioned into austenite being insufficient to convert the originally immobile coherent twin boundaries into general high-angle grain boundaries. ${ }^{[103]}$ It is the most likely dominant mechanism operating in the austenite phase of the DSS during the FSW in this study, as the significantly high fraction of coherent twin boundaries in the BM (see Figures 7(a) and (e)) has been reduced to a small fraction in the SZ (Figures 7(d) and (f)) after FSW. Comparison between the plots of misorientation angle distributions of the austenite phase in the BM and in the SZ of the DSS (Figures 7(a) and (d)), show that the original coherent twin boundaries became increasingly deformed and progressively transformed to general boundaries under severe shear strain at high temperature, induced by the FSW. ${ }^{[100,104]}$ Despite the significantly high level of shear strain, in the present work this transformation has not yet been completed, which may be due to the aforementioned limited strain partitioning into austenite. ${ }^{[103]}$

In the TMAZ of both materials (see Figures 4, 5 and 6), particularly toward the root of the weld (Figures 4(e), 5(f)), fine and ultrafine equiaxed grains have been observed, similar to the formation of fine grains during FSW of other grades of steels. ${ }^{[11,12,47,52,57,105-108]}$ No evidence of acicular ferrite has been seen in the TMAZ of the S275 steel, suggesting that the temperature was below the $\mathrm{Ac}_{1}$ during the FSW. This shows that the temperature in the vicinity of the pin can be significantly lower, possibly below the $\mathrm{Ac}_{1}$ temperature of S275 steel, compared to that close to the tool shoulder.

The grain size refinement in both steels has resulted in a slight increase in hardness in the TMAZs, particularly close to the root of the weld, and also the SAZs, which can be seen in Figures 8(a) and (b). These results are in agreement with those of previous research into FSW of DSS, where the $270 \mathrm{HV}$ hardness of the BM rises to a value of $300 \mathrm{HV}$ in the TMAZ and the SZ ${ }^{[109]}$ Perhaps the hardness map is a best tool for displaying the grain size distribution in different zones of both steels.

A previous study on FSW of microalloyed steel ${ }^{[11]}$ showed minimum measured residual stress components in TMAZ with recrystallized ferrite grains. In the present study, no particular pattern can be observed in the residual stress map (see Figure 11), although the stress magnitude in the weld overall is lower than those of the BM for either steel. The measured ND component of residual stress is tensile for DSS and compressive for S275 steel (Figure 11(b)) which can mirror the geometrically necessary stresses arising from the different thermal expansion coefficients of both materials, resulting in the formation of heterogeneous strain fields in the microstructure, on cooling. Additionally, residual stress typically exists in DSS due to the different nature of the constituent phases. ${ }^{[110,111]}$

\section{B. Texture Development}

Figures 9(a), (c) and 10 show clear systematic rotations of the texture, respectively for ferrite and austenite phases in DSS and ferrite in S275 steel, across the TMAZ and the SZ from far AS to the far RS. Similar behavior has been observed for aluminum, ${ }^{[55]} \mathrm{Ti}-6 \mathrm{Al}-4 \mathrm{~V}$ alloy, ${ }^{[56]}$ and a DH46 microalloyed steel, that like the S275 steel investigated in this study, undergoes phase transformation. ${ }^{[11]}$ This suggests that the entire SZ and TMAZ are dominated by off-axis shear textures, as previously reported for aluminum alloys, pure iron and microalloyed steel. ${ }^{[10,11,112,113]}$ In these materials, the textures within the TMAZ and the SZ were identical and related to one another by two rotation angles; a rotation angle $(\alpha)$ around the ND and a constant tilt angle $(\beta)$ around a direction perpendicular to the ND. Referring to a methodology developed for aluminum, ${ }^{[55]}$ which has been successfully applied to both Ti-6Al-4V $\mathrm{V}^{[56]}$ and microalloyed steel, ${ }^{[11]}$ each undergoing a phase transformation during FSW, the systematic rotation of the texture around the ND as a function of distance, $x$, from the center of the weld in the TD, can be calculated by Eq. [1]. In this relationship, $x_{0}$ is the weld radius, including both SZ and TMAZ, at a point of interest. This implies that the material just in the vicinity of the probe is sheared in the direction of probe tangent, in a manner that results in the shear surface in the post weld 
microstructure having a semi-circular geometry, formed by shear around the trailing edge of the probe.

$$
\alpha=\sin ^{-1}\left(\frac{x}{x_{0}}\right)
$$

The long EBSD maps acquired from the weld cross section (see Figures 9 and 10), covering both steels, in which the orientations, defined by Euler angles with respect to the specimen axes (WD, TD, ND), are transformed to the local shear reference frame $(\theta, Z, r)$ using an in-house developed software in MATLAB, based on the approach developed and demonstrated for aluminum. ${ }^{[55]}$ This includes multiplying the orientation matrix, $G$, for each point in the EBSD maps, by $R_{\alpha}$, to account for rotation angle of $\alpha$ around ND. This is followed by multiplying the outcome by $R_{\beta}$ to rotate the new orientation matrix by a constant angle of $\beta$ around TD, as outlined in Eq. [2]. In these analyses, $\alpha$ is evaluated from Eq. [1], taking into account $x_{0}=4650$ $\mu m$ for the DSS on AS, and $x_{0}=7038 \mu m$ for the S275 on RS. For clockwise rotations, $\alpha$ has been considered negative and positive for rotations anti-clockwise. The slightly smaller radius of the weld on the AS may be due to the forward motion of the tool that has an opposite effect on the radius on the RS of the weld due to opposing direction of motion. ${ }^{[55]}$

$$
\begin{gathered}
G_{r}=G R_{\alpha} R_{\beta}, \\
R_{\alpha}=\left(\begin{array}{ccc}
\cos \alpha & \sin \alpha & 0 \\
-\sin \alpha & \cos \alpha & 0 \\
0 & 0 & 1
\end{array}\right), \\
R_{\beta}=\left(\begin{array}{ccc}
1 & 0 & 0 \\
0 & \cos \beta & \sin \beta \\
0 & -\sin \beta & \cos \beta
\end{array}\right)
\end{gathered}
$$

However, for the weld investigated in this study, rotation of the EBSD maps from the sample reference frame (WD, TD, ND), based on the methodology described by Eqs. 1 and 2, was insufficient to bring the polefigures to the local shear reference frame $(\theta, Z, r)$. Firstly, as opposed to the aluminum ${ }^{[55]}$ from which the above methodology was developed, the $\beta$ rotation angle around TD was not constant for different regions of either steels in the dissimilar weld investigated in this study. In the SZ of each steel, the $\beta$ angle appears to be constant at $60 \mathrm{deg}$, while by entering the TMAZ from the SZ in both sides of the weld the $\beta$ angle decreases to a minimum of $50 \mathrm{deg}$ on the AS and $49 \mathrm{deg}$ on the RS. This is shown in Figure 12(b) as a function of distance from the center of the weld for both materials. In fact, the position the $\beta$ angle starts to decline, is coincidently the start of TMAZ on both sides of the weld. A sharp TMAZ on AS and more diffused TMAZ on RS is clearly observed. This is likely to be due to the tri-flat geometry of the six sided probe, which has three flat sides and three curved sides with different radii, and different tapering angles. Figure 12(a) shows schematically that $\beta_{1}$ and $\beta_{2}$ are the tapering angles, respectively, for the curved sides with a radius $R$, and flat sides with a radius $r$.

Secondly, the $R_{\alpha}$ and $R_{\beta}$ rotations around the ND and TD, respectively, were necessary but, not sufficient, to rotate the EBSD maps from the sample reference frame to the local shear reference frame. Instead, the outcome of multiplying the orientation matrix, $G$, by $R_{\alpha}$ and $R_{\beta}$ (Eq. [2]) needed to be multiplied further by $R_{\omega}$, to account for additional rotation around WD. This is shown schematically in Figure 12(c) for two imaginary poles shown by solid circles, one on the left hand side representing DSS on AS and the other on the right hand side representing the $\mathrm{S} 275$ on $\mathrm{RS}$, that required rotation to the center of the polefigure to match the local shear reference frame. Multiplying the orientation matrix, $G$, by $R_{\alpha}$ and $R_{\beta}$ rotated the poles to positions on the WD plane that are represented by dotted circles (see Figure 12(c)), and require further rotation by $\omega$ to rotate to the center. Similarly to $\alpha$, for clockwise rotations (i.e., AS of the weld) $\omega$ has been considered negative, and positive for anti-clockwise (i.e., RS of the weld). $\omega$ changes as a function of distance from the center of the weld (see Figure 12(b)) which appears to be fairly linear in the SZ and become complicated in the TMAZ of both materials. For the purpose of visualizing the applied $\omega$ rotations, solid rectangles representing individual EBSD maps were rotated by the actual $\omega$ angles, as a function of distance from the center of the weld overlaid on the optical micrograph of the weld cross section, shown in Figure 12(d). This implies that the local shear reference frame is rotating around WD as a function of distance from the center of the weld, which is crucially dependant on the geometry of the probe. Hence, to account for the additional $\omega$ rotation, the methodology presented in Eq. [2] is corrected to the form shown in Eq. [3], in which $R_{\alpha}$ and $R_{\beta}$ are exactly the same as those presented in Eq. [2].

$$
\begin{aligned}
G_{r} & =G R_{\alpha} R_{\beta} R_{\omega}, \\
R_{\omega} & =\left(\begin{array}{ccc}
\cos \omega & 0 & -\sin \omega \\
0 & 1 & 0 \\
\sin \omega & 0 & \cos \omega
\end{array}\right),
\end{aligned}
$$

The rotated EBSD maps, which describe the orientation of each data point with respect to the local shear reference frame, are shown in Figures 13 and 14 for the DSS and S275 steel, respectively. The rotated map of the DSS (Figure 13(b)) is dominated by near $\langle 101\rangle$ and $\langle 111\rangle$ crystal directions parallel to the $r$ direction of the local shear reference frame. On the RS, the rotated map of S275 steel (Figure 14) is strongly dominated by the $\langle 101\rangle$ crystal orientation (green) up to the interface with the HAZ, where the texture fades away. These corrected data presented in Figures 13 and 14 allow detailed analyses of the dominant texture components during FSW relative to the shear reference frame at a point of interest across the weld. Shear textures are commonly defined in terms of crystallographic plane $\{h k l\}$ and direction $\langle u v w\rangle$ aligned parallel to the shear plane normal $(Z)$ and shear direction $(\theta)$, respectively. 

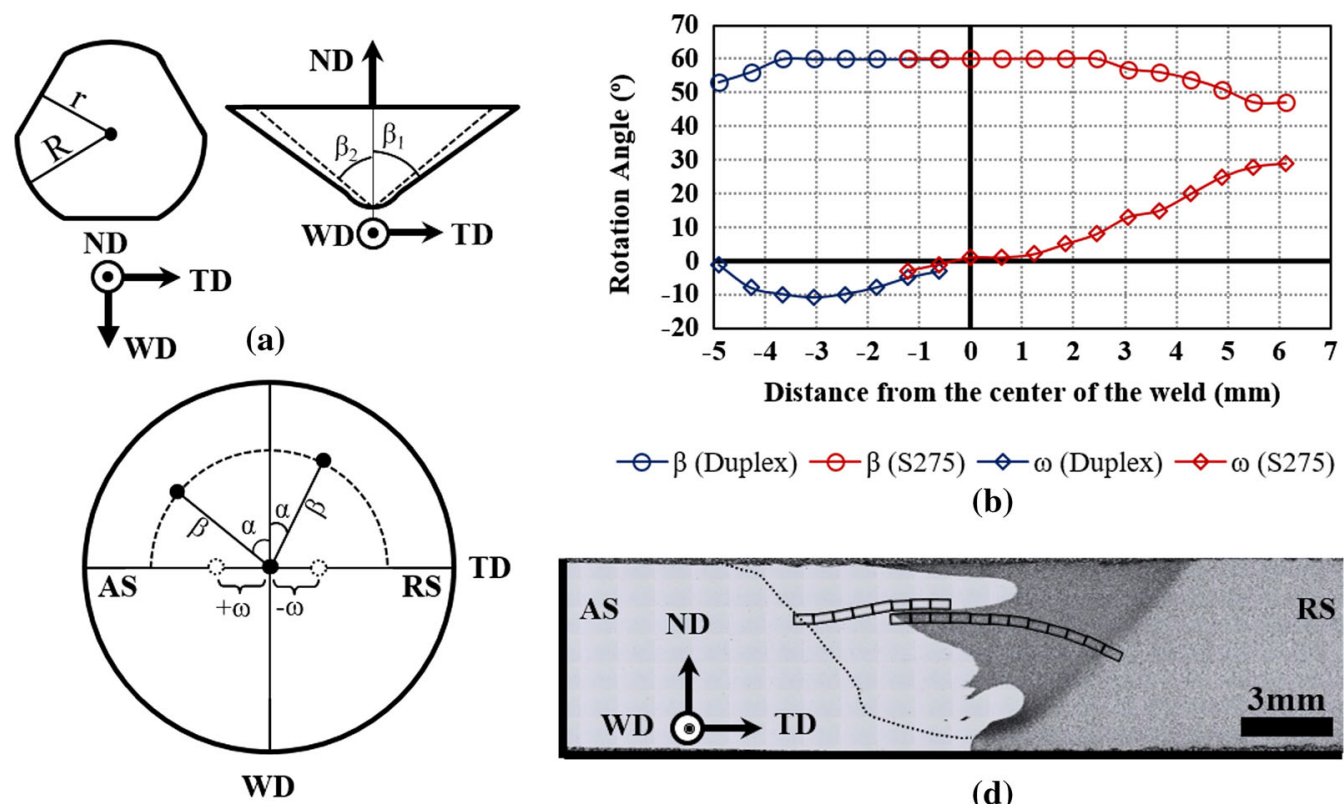

$\neg \beta$ (Duplex) $\odot \beta$ (S275) $\diamond \omega$ (Duplex) $\diamond-\omega(\mathrm{S} 275)$

(b)

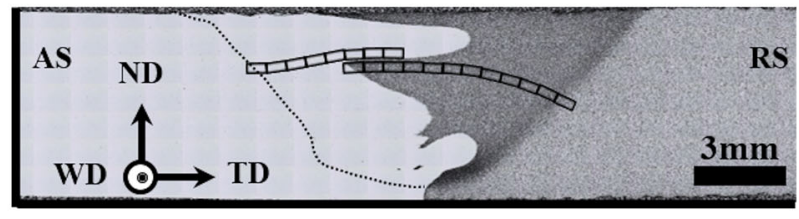

(c)

(d)

Fig. 12-(a) Schematic illustration of the cross section of the probe in WD-TD and ND-TD plane of views, $(b)$ plot of actual applied rotation angles $\beta$ and $\omega$ as a function of distance from the center of the weld, $x,(c)$ schematic polefigure diagram of the location of one of the strong poles (i.e., (101) for bcc, and (111) for fcc) in the sample reference frame and the application of rotation matrix (i.e., rotation by $\alpha$, $\beta$, and $\omega)$ to rotate it to the local shear reference frame, and $(d)$ optical micrograph of the weld cross section with schematic illustration of $\omega$ rotation of the EBSD maps as a function of distance from far AS to far RS.

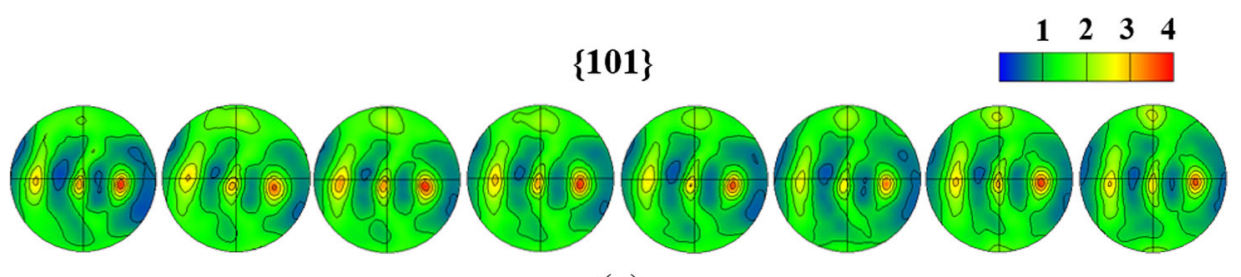

(a)

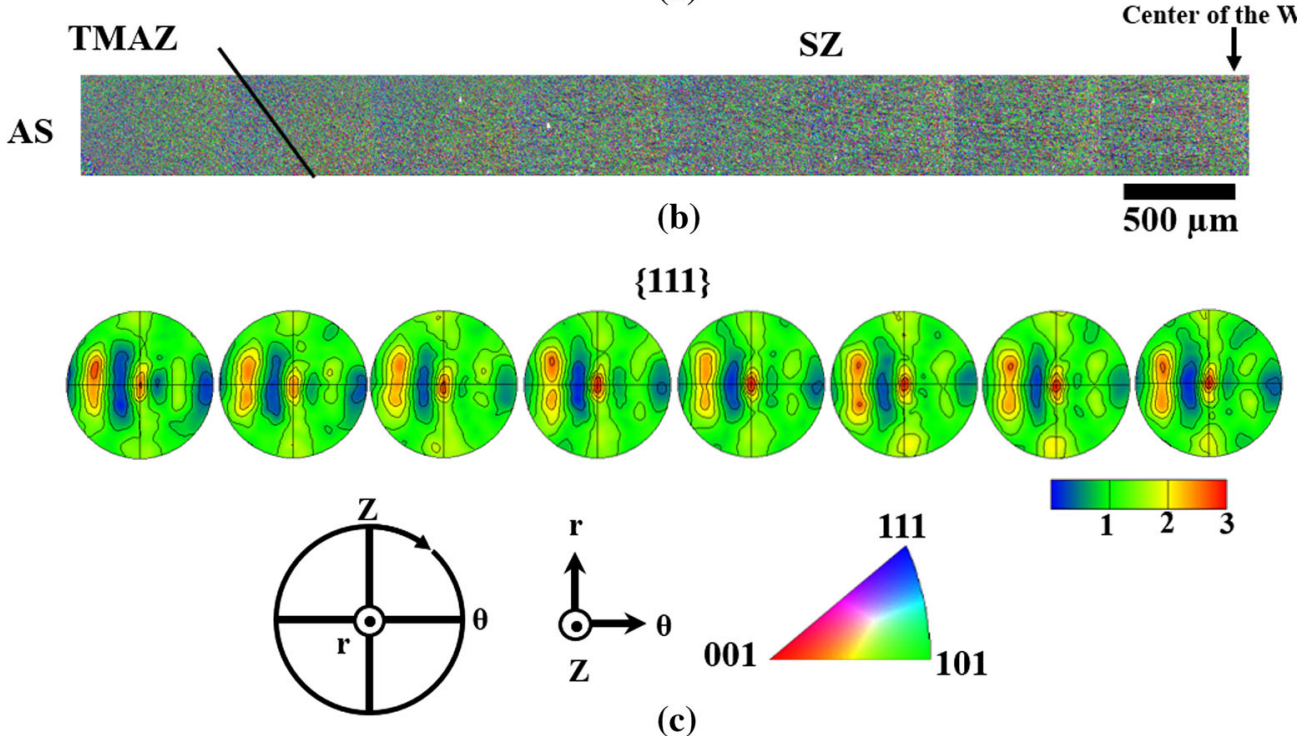

Fig. 13-EBSD IPF coloring across TMAZ and SZ of the DSS after rotation to the local shear reference frame $(\theta, Z, r)$, along with their resultant polefigures. (a) (101) polefigures of ferrite in DSS, (b) EBSD IPF maps with respect to ' $r$ ' direction, and $(c)$ (111) polefigures of austenite in DSS. The polefigures are presented with $Z$ on top, shear direction $(\theta)$ on the right, and $r$ in the center. 


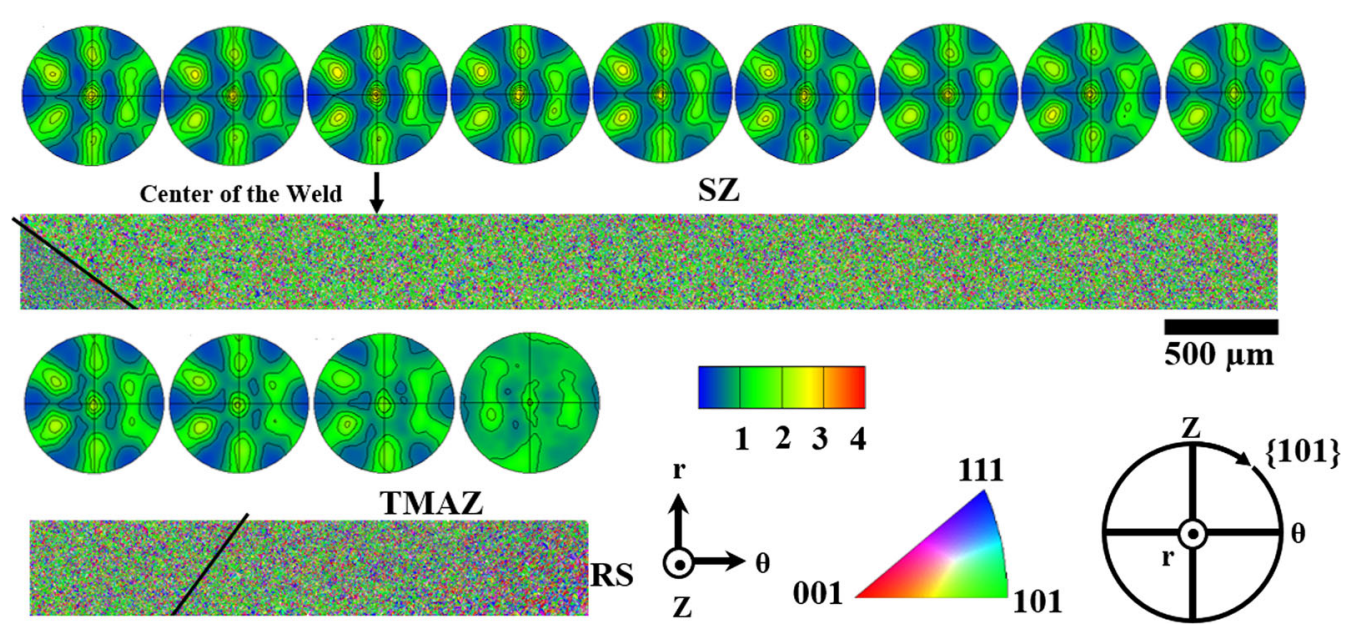

Fig. 14 -EBSD IPF coloring across SZ and TMAZ of the S275 steel after rotation to the local shear reference frame $(\theta, Z, r)$ with respect to ' $r$ ' direction, along with their resultant (101) polefigures. The polefigures are presented with $Z$ on top, shear direction $(\theta)$ on the right, and $r$ in the center.

Table II. Ideal Crystallographic Orientations Induced During Simple Shear Deformation in bec and fcc Materials ${ }^{[14]}$

\begin{tabular}{|c|c|c|c|c|c|}
\hline \multirow[b]{2}{*}{ Crystal Structure } & \multirow[b]{2}{*}{ Shear Component } & $\multirow[b]{2}{*}{h k l}<u v w>$ & \multicolumn{3}{|c|}{ Euler Angles (Deg) } \\
\hline & & & $\varphi_{1}$ & $\varphi$ & $\varphi_{2}$ \\
\hline \multirow[t]{10}{*}{ fcc } & $A_{1}^{*}$ & $\{111\}\langle\overline{1} 1 \overline{2}\rangle$ & $35.3 / 215.3$ & 45 & 0 \\
\hline & & & $125.3 / 305.3$ & 90 & 45 \\
\hline & $A_{2}^{*}$ & $\{111\}\langle 111 \overline{2}\rangle$ & $144.7 / 324.7$ & 45 & 0 \\
\hline & & & $54.7 / 234.7$ & 90 & 45 \\
\hline & $A$ & $\{1 \overline{1} 1\}\langle 110\rangle$ & 0 & 35.3 & 45 \\
\hline & $\bar{A}$ & $\{1 \overline{1} 1\}\langle\overline{1} \overline{1} 0\rangle$ & 180 & 35.3 & 45 \\
\hline & $B$ & $\{1 \overline{1} 2\}\langle 110\rangle$ & $0 / 120 / 240$ & 54.7 & 45 \\
\hline & $\bar{B}$ & $\{11 \overline{2}\}\langle 1 \overline{1} 0\rangle$ & $60 / 180 / 300$ & 54.7 & 45 \\
\hline & $C$ & $\{001\}\langle 110\rangle$ & $90 / 270$ & 45 & 0 \\
\hline & & & $0 / 180$ & 90 & 45 \\
\hline \multirow[t]{10}{*}{ bcc } & $D_{1}$ & $\{\overline{1} \overline{1} 2\}\langle 111\rangle$ & $54.7 / 234.7$ & 45 & 0 \\
\hline & & & $144.7 / 324.7$ & 90 & 45 \\
\hline & $D_{2}$ & $\{11 \overline{2}\}\langle 111\rangle$ & $125.3 / 305.3$ & 45 & 0 \\
\hline & & & $35.3 / 215.3$ & 90 & 45 \\
\hline & $E$ & $\{\underline{1} \underline{1} 0\}\langle 1 \overline{1} 1\rangle$ & 90 & 35.3 & 45 \\
\hline & $\bar{E}$ & $\{\overline{1} 10\}\langle 1 \overline{1} 1\rangle$ & 270 & 35.3 & 45 \\
\hline & $J$ & $\{110\}\langle 1 \overline{1} 2\rangle$ & $90 / 210 / 330$ & 54.7 & 45 \\
\hline & $\bar{J}$ & $\{1 \overline{1} 0\}\langle\overline{1} 1 \overline{2}\rangle$ & $30 / 150 / 270$ & 54.7 & 45 \\
\hline & $F$ & $\{110\}\langle 001\rangle$ & $0 / 180$ & 45 & 0 \\
\hline & & & $90 / 270$ & 90 & 45 \\
\hline
\end{tabular}

Accordingly, this is the alignment of the $\{111\}$ slip planes with the $Z$ and the $\langle 110\rangle$ slip direction with $\theta$ in fcc materials. In bcc materials, the ideal orientations formed by simple shear deformation are along two partial fibers of $\{h k l\}\langle 111\rangle$ and $\{110\}\langle u v w\rangle$. For both fcc and bcc crystal structures, these contain different ideal shear components that are summarized in Table II..$^{[114]}$

For both materials used in this study, shear deformations are taking place at various temperatures, depending on the position within the weld. Referring back to the microstructural observations discussed earlier, the temperature in the S275 steel is $\leq \mathrm{Ac}_{1}$ temperature in which the microstructure is either entirely or predominantly bcc ferrite. In the DSS side, although the temperature is expected to be slightly higher, the two-phase microstructure of DSS is maintained, as the temperature is far below the austenite - ferrite transformation temperature range $(\approx$ $1300{ }^{\circ} \mathrm{C}$ to $1400{ }^{\circ} \mathrm{C}$ ). Hence, the deformation textures with respect to the shear reference frame in S275 steel and the ferrite phase of DSS are expected to be similar to the ideal shear deformation in $b c c$ metal, and that of the austenite phase of DSS should contain ideal shear deformation components of $f c c$ metal. The experimentally measured textures of the S275 steel and both ferrite and austenite of the DSS, following the rotation corrections from the sample reference frame to the shear reference frame, are compared with ideal shear deformations of $b c c$ and $f c c$ metals, and the results are shown in Figure 15. 
After correcting the data for rotation from the sample reference frame (WD, TD, ND) to the local shear reference frame $(\theta, Z, r)$, the rotated polefigures across TMAZ and SZ of both materials become almost identical, with slight differences in intensity of the poles as a function of position (see Figures 13 and 14). This confirms that the deformation textures are simple shear, resulting from the final severe deformation in the material, caused by the trailing edge of the probe. ${ }^{[11,55,56,115]}$ Figure $15(\mathrm{a})$, shows the $A, \bar{A}, B$, and $\bar{B}$ shear texture components for $\{111\}$ crystallographic planes of fcc metals (see Table II) superimposed on the $\{111\}$ polefigure of austenite in DSS from the center of the weld, with respect to the local shear reference frame. It can be observed that the poles match reasonably well with the projection of the $A, \bar{A}, B$, and $\bar{B}$ ideal shear texture components of fcc metals (Figure 15(a)). This is further confirmed in Figure 16(a) which shows the rotated data in orientation distribution function (ODF) space, emphasizing the dominance of $A, \bar{A}, B$, and $\bar{B}$ components.

Similarly, Figure 15(b) and c, respectively, show the ideal shear texture components for $\{101\}$ crystal- lographic planes of bcc metals superimposed on the $\{101\}$ polefigures of ferrite in DSS and ferrite in S275 steel, both from the center of the weld, with respect to the local shear reference frame. Their respective ODFs are shown in Figures 16(b) and (c), with the ideal shear texture components for bcc metals superimposed. Figure 16(b) shows that $D_{1}, D_{2}, I, \bar{I}$, and $F$ are the dominant shear texture components in the ferrite phase of DSS, while Figure 16(c) shows that $D_{1}, D_{2}, E, \bar{E}$, and $F$ are the dominant shear texture components in S275 steel.

The excellent match between the rotated data of the S275 steel, in both polefigure (see Figure 15(c)) and ODF (see Figure 16(c)) forms, and the projection of $D_{1}$, $D_{2}, E, \bar{E}$, and $F$ ideal shear texture components of bcc metal, indicate that the deformation occurs at or around the $\mathrm{Ac}_{1}$ temperature where the microstructure is predominantly ferrite. A well-defined $D$ shear texture component had been observed during friction stir processing of pure iron, ${ }^{[57]}$ and FSW of microalloyed stee ${ }^{[11]}$ where polygonal ferrite dominated the entire microstructure of the former and TMAZ of the latter. In this study, the observed microstructures of the SZ and

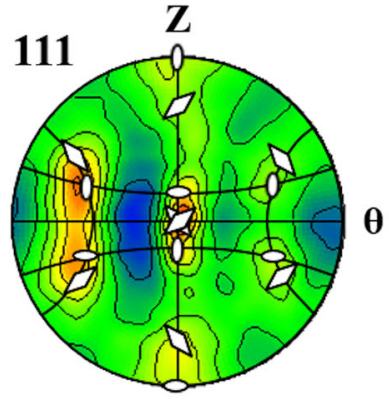

(a)

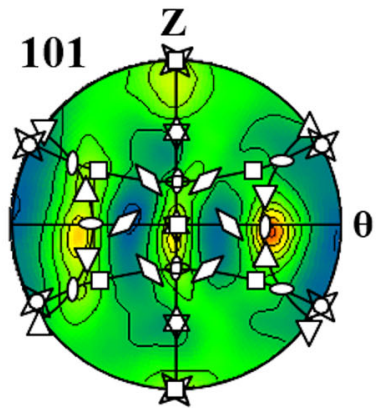

(b)

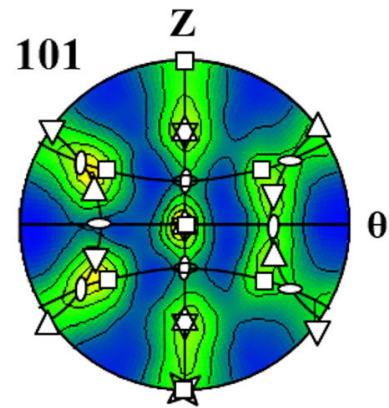

(c)
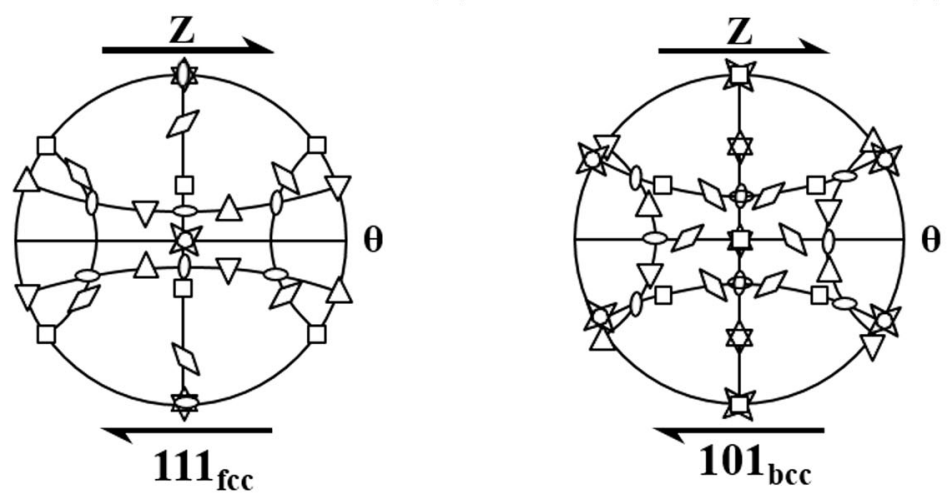

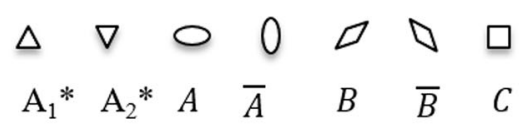

(d)

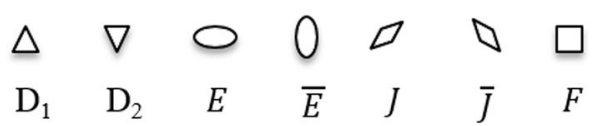

(e)

Fig. 15-Polefigures displaying the texture in terms of the local shear reference frame (i.e., shear direction $(\theta)$, and shear plane normal $(Z))$ of $(a)$ $\{111\}$ crystallographic plane of austenite phase in DSS, with $A, \bar{A}, B$, and $\bar{B}$ of the ideal shear deformation components for fcc metals superimposed, $(b)$ and $(c)\{101\}$ crystallographic plane of ferrite in both DSS and S275 steel, respectively, with $D_{1}, D_{2}, E, \bar{E}$, and $F$ of the ideal shear deformation components for bcc metals superimposed. $(d)$ and $(e)$ are the ideal shear deformation components for fcc and bcc metals, respectively, for which the data are taken from Ref. [114]. 


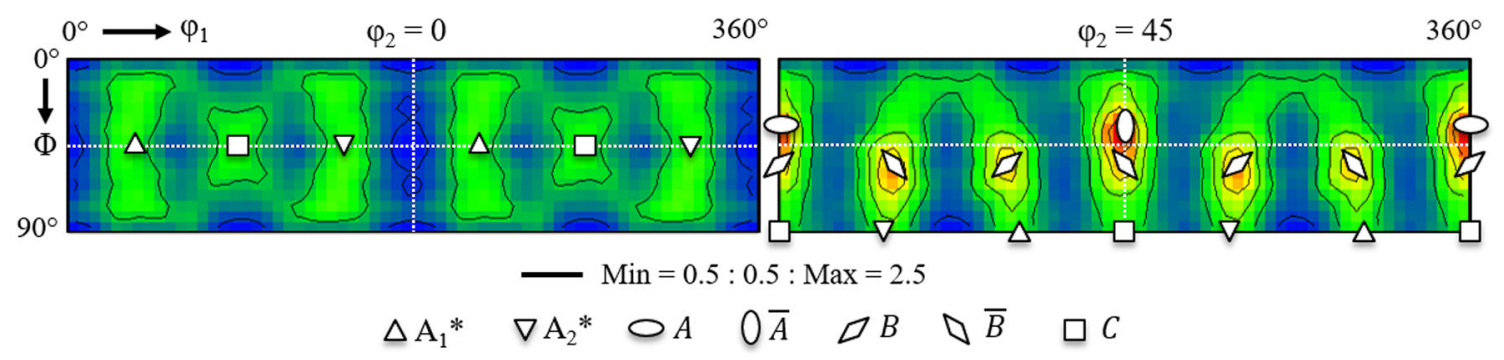

(a)

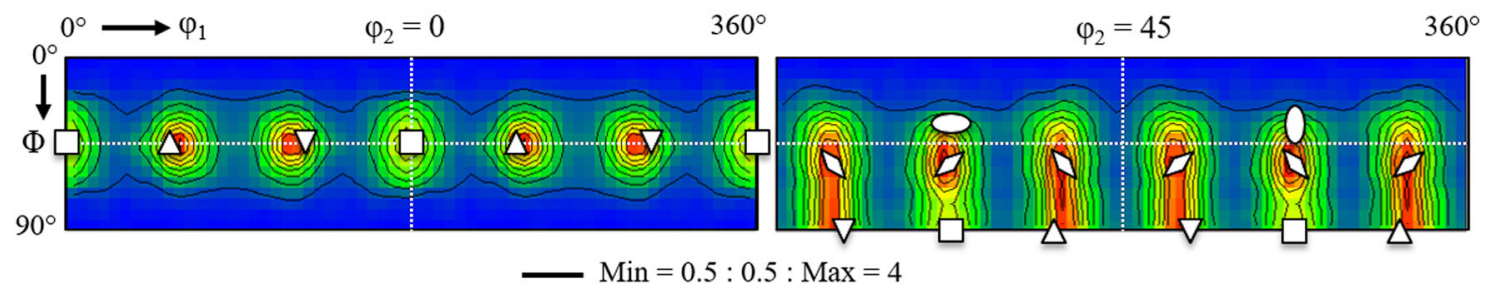

(b)

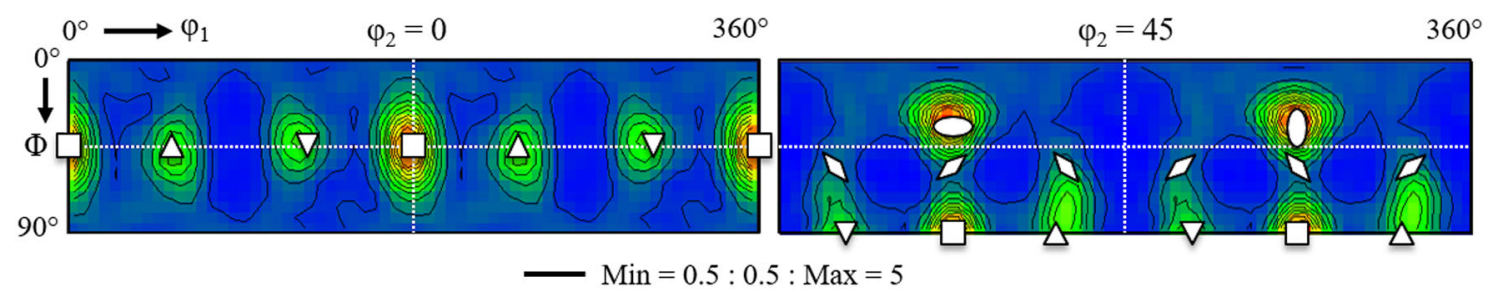

$\begin{array}{lllllll}\triangle \mathrm{D}_{1} & \nabla \mathrm{D}_{2} & \bigcirc E & O \bar{E} & \square J & \square & \square F\end{array}$

(c)

Fig. 16- $\varphi_{2}=0^{\circ}$ and $\varphi_{2}=45^{\circ}$ ODF sections for the rotated dataset in the local shear reference frame across the whole weld (i.e., TMAZ and SZ of both DSS and S275 steel) for $(a)$ austenite phase of DSS with the ideal shear components of fcc metals superimposed; $(b)$ and $(c)$ ferrite phase in DSS and S275 steel, respectively, with the ideal shear components of bcc metals superimposed. The data are calculated based on WIMV method using a data clustering angle of $3 \mathrm{deg}$ and a Gaussian half width of $5 \mathrm{deg}$. The Euler angles of ideal shear texture components for both fcc and bec metals are provided in Table II.

TMAZ of S275 steel are primarily polygonal ferrite (see Figure 5) with identical resultant texture in all these zones (see Figure 14).

In DSS side of the weld, despite superior matches between the corrected ODFs of both austenite and ferrite phases and their relevant ideal shear texture components (see Figures 16(a) and (b)), their respective polefigures (see Figures 15(a) and (b)) show that the intensities of some of the poles are significantly higher. This has resulted in the faded appearance of the poles with lower intensities, to a degree that a match between the weak poles and the projection of the ideal shear texture components is hardly possible. Such variant intensities in the poles have been observed during FSW of Ti-6Al-4V alloy ${ }^{[56]}$ and microalloyed steel, ${ }^{[1]]}$ both undergoing phase transformation. These were recognized as evidence of significant variant selection during $\alpha \rightarrow \beta,{ }^{[56]}$ and austenite $\rightarrow$ ferrite ${ }^{[11]}$ phase transformations, respectively, due possibly to the directionality of the heat transfer, and the thermally induced stresses in the weld as a result of constrained thermal contraction during cooling. ${ }^{[5]}$ However, this is unlikely to be the case in this study, since during FSW, the temperature in the AS, where the DSS is located, reaches temperatures between $\mathrm{Ac}_{1}$ and $\mathrm{Ac}_{3}$ for the S275 steel which is significantly lower than $1000{ }^{\circ} \mathrm{C}$. As mentioned previously, at this temperature, the two-phase microstructure of the DSS is maintained, with no changes in the fraction of ferrite and austenite, while both phases undergo shear deformation simultaneously. This may be caused by the preferential partitioning of strain into ferrite during FSW, leading to differences in the stress state across the grains of both phases. ${ }^{[116,117]}$ This results in variations in the selection of slip systems in different grain regions such that some slip systems accommodate the deformation more than the others. ${ }^{[16,117]}$

Comparisons between these observations and those reported for pure iron ${ }^{[57]}$ and microalloyed stee ${ }^{[11]}$ imply that FSW results in well-defined D shear texture components in bcc ferrite, disregarding the cooling rate and chemical compositions. However, differences are observed in the nature of the shear deformations in single-phase ferrite compared to the ferrite phase in a dual-phase duplex steel. Figure 16(b) clearly shows that preferential partitioning of strain into ferrite in DSS has resulted in the development of strong $I$ and $\bar{I}$ shear 
texture components, but no evidence of $E$ and $\bar{E}$ components. On the contrary, Figure 16(c) shows that in single-phase ferrite of S275 steel, $E$ and $\bar{E}$ are the dominant shear texture components, with no traces of $I$ and $\bar{I}$ components. Nevertheless, these observations suggest that the texture across the whole weld between dissimilar steels is simple shear texture with respect to the shear reference frame.

Finally, welds between dissimilar metals and alloys are becoming increasingly an important part of manufacturing of engineering components and structures across different industries. These include joining dissimilar steels for applications in shipbuilding and oil and gas industries, and lightweight grades of aluminum to aluminum or to steels or magnesium in automotive and aerospace industries. ${ }^{[19,24,27,39]}$ Welding stainless steels directly to carbon steel is generally for the purpose of cost reduction, as constructing the entire structure from stainless steels may be extremely expensive due to their approximately ten times higher prices than that of carbon steels. Therefore, the use of stainless steels can be minimized, where possible, by replacing and joining them to carbon steel through an appropriate welding technique such as FSW, without compromising the integrity of the structure. However, several problems might arise from welding dissimilar materials due to their different inherent thermophysical and thermomechanical properties such as dissimilar heat conductivity, thermal expansion, and melting temperatures. ${ }^{[118-121]}$ All these need to be carefully taken into consideration while joining dissimilar materials using FSW, to preserve the desired mechanical properties on both sides of the weld. For instance, joining stainless steels to other materials can lead to the deterioration of their stainless properties with enhanced susceptibility to corrosion. ${ }^{[121]}$ The results presented in this paper can be used by welding engineers to understand the development of microstructure in different regions of the weld during FSW of dissimilar steels, whereby appropriate process parameters can be implemented to achieve desired microstructures. Furthermore, the knowledge generated on microstructure evolution and the methodology developed for predicting texture evolution as a function of tool's geometry can be used for validation and augmentation of predictive microstructure and materials models, particularly those based on crystal plasticity.

\section{CONCLUSION}

In this study, evolution of microstructure and crystallographic texture during dissimilar friction stir welding of duplex stainless steel to a low carbon-manganese structural steel type S275 were investigated. The main results of this research are as follows:

- The friction stir welding of dissimilar duplex stainless steel to $\mathrm{S} 275$ steel resulted in the formation of fine and ultrafine equiaxed grains in the SZ, SAZ, and TMAZ of both materials. The observed refinement can be due to CDRX of ferrite in S275 steel and ferrite phase of DSS, and DDRX of austenite phase of DSS, under large shear strains induced by the FSW and severe undercooling.

- It is suggested that the peak temperature achieved in the SZ of S275 steel during FSW was close to the lower end of $\mathrm{Ac}_{1}$ to $\mathrm{Ac}_{3}$ temperature range, resulting in a mixed microstructure of predominantly polygonal ferrite with a small fraction of acicular ferrite, due to the austenite-ferrite transformation on cooling. This, however, can be slightly higher in the SZ of DSS on the AS, due to the same direction of tool rotational and forward motions, and also the higher strength of the DSS.

- The deformation in the S275 occurred at or around the $\mathrm{Ac}_{1}$ temperature in the presence of predominantly ferrite phase. The deformation in ferrite in all zones, including SZ, TMAZ, and the SAZ, is shear dominated by $D_{1}\{\overline{1} \overline{1} 2\}\langle 111\rangle, D_{2}\{11 \overline{2}\}\langle 111\rangle, E\{110\}$ $\langle 1 \overline{1} 1\rangle, \bar{E}\{\overline{1} \overline{1} 0\}\langle 1 \overline{1} 1\rangle$ and $F\{110\}\langle 001\rangle$ simple shear texture components.

- The deformation in the DSS occurred at temperatures between $\mathrm{Ac}_{1}$ and $\mathrm{Ac}_{3}$ of the $\mathrm{S} 275$ steel, where evidence of preferential partitioning of strain into ferrite phase was observed. The deformation in both ferrite and austenite phases, with the fractions maintained as those of the BM, are simple shear dominated by $A\{1 \overline{1} 1\}\langle 110\rangle, \bar{A}\{1 \overline{1} 1\}\langle\overline{1} \overline{1} 0\rangle, B\{1 \overline{1} 2\}$ $\langle 110\rangle$ and $\bar{B}\{\overline{1} 1 \overline{2}\}\langle\overline{1} \overline{1} 0\rangle$ ideal shear texture components for fcc metals in the austenite, and $D_{1}\{\overline{1} 12\}$ $\langle 111\rangle, D_{2}\{11 \overline{2}\}\langle 111\rangle, I\{110\}\langle 1 \overline{1} 2\rangle, \bar{I}\{\overline{1} \overline{1} 0\}\langle\overline{1} 1 \overline{2}\rangle$ and $F\{110\}\langle 001\rangle$ ideal shear texture components for bcc metals in the ferrite.

- The preferential partitioning of strain into the ferrite phase of the DSS and limitation in deformation has resulted in the development of $I$ and $\bar{I}$ shear texture components, as opposed to $E$ and $\bar{E}$ in ferrite of the single-phase $\mathrm{S} 275$ steel, although, $D_{1}, D_{2}$, and $F$ shear components were developed in both materials additionally. A comparison between the deformation behaviors in these steels with previous studies suggests that disregarding chemical composition, $D_{1}$, $D_{2}$, and $F$ are the favorable shear texture components developed in ferrite during FSW.

\section{ACKNOWLEDGMENTS}

The authors would like to acknowledge the support provided by the Advanced Forming Research Center (AFRC), University of Strathclyde, which receives partial financial support from the UK's High Value Manufacturing CATAPULT. Dr N.A. McPherson, formerly of BAE Systems Marine, Govan, Glasgow, is thanked for providing the FSW specimens.

\section{OPEN ACCESS}

This article is distributed under the terms of the Creative Commons Attribution 4.0 International License (http://creativecommons.org/licenses/by/4.0/), 
which permits unrestricted use, distribution, and reproduction in any medium, provided you give appropriate credit to the original author(s) and the source, provide a link to the Creative Commons license, and indicate if changes were made.

\section{REFERENCES}

1. W. M. Thomas, E. D. Nicholas, J. C. Needham, M. G. Murch, P. Temple-Smith, C. J. Dawes, International Patent application no. PCT/GB92/02203 and GB Patent application No. $9125978 \cdot 8$ and US Patent application no. 5,460,317, 1991.

2. W.M. Thomas and C.J. Dawes: Weld, 1996, vol. 75, pp. 41-45.

3. G.A. Moraitis and G.N. Labeas: Sci. Technol. Weld. Join., 2010, vol. 15 , pp. $177-84$

4. M. Wade and A.P. Reynolds: Sci. Technol. Weld. Join., 2010, vol. 15 , pp. 64-69.

5. R. Nandan, T. DebRoy, and H.K.D.H. Bhadeshia: Prog. Mater Sci., 2008, vol. 53, pp. 980-1023.

6. Y.H. Yin, N. Sun, T.H. North, and S.S. Hu: Sci. Technol. Weld. Join., 2010, vol. 15, pp. 81-86.

7. G. Lütjering, J. C. Williams: Titanium. (Springer, New York, 2007), pp. 109-113.

8. J. Young, D.P. Field, and T.W. Nelson: Metall. Mater. Trans. A, 2013, vol. 44, pp. 3167-75.

9. M. Gosh, K. Kumar, and R.S. Mishra: Scr. Mater., 2010, vol. 63, pp. 851-54.

10. S. Mironov, Y.S. Sato, H. Kokawa, H. Inoue, and S. Tsuge: Acta Mater., 2011, vol. 59, pp. 5472-81.

11. S. Rahimi, B.P. Wynne, and T.N. Baker: Metall. Mater. Trans. $A$, 2017, vol. 48, pp. 362-78.

12. Y.S. Sato, T.W. Nelson, and C.J. Sterling: Acta Mater., 2005, vol. 53, pp. 637-45.

13. C.Y. Lee, D.H. Choi, Y.M. Yeon, and S.B. Jung: Sci. Technol. Weld. Join., 2009, vol. 14, pp. 216-20.

14. G. Benghalia, S. Rahimi, J. Wood, H. Coules, and S. Paddea: Mater Perform. Charact., 2018, vol. 7 (4), pp. 606-29.

15. W. Rae, Z. Lomas, M. Jackson, and S. Rahimi: Mater. Charact., 2017, vol. 132, pp. 10-19.

16. D. Easton, J. Wood, S. Rahimi, A. Galloway, Y. Zhang, and C. Hardie: IEEE T. Plasma Sci., 2016, vol. 44, pp. 1625-30.

17. S. Rahimi, K. Mehrez, and T.J. Marrow: Corros Eng Sci Techn, 2015, vol. 51, pp. 383-91.

18. S. Rahimi and T.J. Marrow: Fatigue Fract. Eng. Mater. Struct., 2012, vol. 35, pp. 359-73.

19. H.K.D.H. Bhadeshia: Sci. Technol. Weld. Join., 2010, vol. 15, pp. 646-47.

20. M. Jafarzadegan, A.H. Feng, A. Abdollah-Zadeh, T. Saeid, J. Shen, and H. Assadi: Mater. Charact., 2012, vol. 74, pp. 28-41.

21. P. Xue, D.R. Ni, D. Wang, B.I. Xiao, and Z.Y. Ma: Mater. Sci. Eng. A, 2011, vol. 528, pp. 4683-89.

22. R.S. Coelho, A. Kostka, J.F. dos Santos, and A. Kaysser-Pyzalla: Mater. Sci. Eng. A, 2012, vol. 556, pp. 175-83.

23. X. Liu, S. Lan, and J. Ni: Mater. Des., 2014, vol. 59, pp. 50-62.

24. C.B. Jagadeesha: Mater. Sci. Eng. A, 2014, vol. 616, pp. 55-62.

25. A. Aghaei and K. Dehghani: Int. J. Adv. Manuf. Technol., 2015, vol. 77, pp. 573-79.

26. C. Shen, J. Zhang, and J. Ge: J. Environ. Sci., 2011, vol. 23, pp. 32-35.

27. H. Kasai, Y. Morisada, and H. Fujii: Mater. Sci. Eng. A, 2015, vol. 624 , pp. $250-55$.

28. J. Guo, P. Gougeon, and X.G. Chen: Mater. Sci. Eng. A, 2012, vol. 553 , pp. $149-56$.

29. K. Ishida, Y. Gao, K. Nagatsuka, M. Takahashi, and K. Nakata: J. Alloys Compd, 2015, vol. 630, pp. 172-77.

30. L. Karlsson, E.L. Berqvist, and H. Larsson: Weld. World, 2002, vol. 46, pp. 10-14.

31. W.M. Thomas, P.L. Threadgill, and E.D. Nicholas: Sci. Technol. Weld. Join., 1999, vol. 4, pp. 365-72.

32. J. Rodriguez and A.J. Ramirez: Sci. Technol. Weld. Join., 2014, vol. 19 , pp. 343-49.
33. H. Jamshidi Aval, S. Serajzadeh, A.H. Kokabi, and A. Loureiro: Sci. Technol. Weld. Join., 2011, vol. vol. 16, pp. 597-604.

34. C.G. Rhodes, M.W. Mahoney, W.H. Bingel, R.A. Spurling, and C.C. Bampton: Scr. Mater., 1997, vol. 36, pp. 69-73.

35. D.J. Shindo, A.R. Rivera, and L.E. Murr: J. Mater. Sci., 2002, vol. 37, pp. 4999-5005.

36. G. Liu, L.E. Murr, C.-S. Niou, J.C. McClure, and F.R. Vega: Scr. Mater., 1997, vol. 37, pp. 355-59.

37. M. Amirizad, A.H. Kokabi, M.A. Gharacheh, R. Sarrafi, B. Shalshi, and M. Azizieh: Mater. Lett., 2006, vol. 60, pp. 565-68.

38. R.A. Prado, L.E. Murr, K.F. Soto, and J.C. McClure: Mater. Sci. Eng A, 2003, vol. 349, pp. 156-65.

39. Y. Li, L.E. Murr, and J.C. McClure: Mater. Sci. Eng A, 1999, vol. 271, pp. 213-23.

40. R.S. Mishra and Z.Y. Ma: Mater. Sci. Eng. A, 2005, vol. 50, pp. 1-78.

41. K. Kumar and S.V. Kailas: Mater. Sci. Eng. A, 2008, vol. 485, pp. 367-74.

42. R. Rai, A. De, H.K.D.H. Bhadeshia, and T. DebRoy: Sci. Technol. Weld. Join., 2011, vol. 16, pp. 325-42.

43. T. Weinberger, N. Enzinger, and H. Cerjak: Sci. Technol. Weld. Join., 2009, vol. 14, pp. 210-15.

44. Y.C. Chen, H. Fujii, T. Tsumura, Y. Kitagawa, K. Nakata, K. Ikeuchi, K. Matsubayashi, Y. Michishita, Y. Fujiya, and J. Katoh: Sci. Technol. Weld. Join., 2009, vol. 14, pp. 197-201.

45. M.C. Theodoro, V.F. Pereira, P.R. Mei, and A.J. Ramirez: Metall. Mater. Trans. B, 2015, vol. 46, pp. 1440-47.

46. B.P. Logan, A.I. Toumpis, A.M. Galloway, N.A. McPherson, and S.J. Hambling: Sci. Technol. Weld. Join., 2016, vol. 21, pp. 11-19.

47. Y.S. Sato, T.W. Nelson, C.J. Sterling, R.J. Steel, and C.O. Pettersson: Mater. Sci. Eng. A, 2005, vol. 397, pp. 76-384.

48. S.H.C. Park, Y.S. Sato, H. Kokawa, K. Okamoto, S. Hirano, and M. Inagaki: Scr. Mater., 2003, vol. 49, pp. 1175-80.

49. A. Toumpis, A. Galloway, S. Cater, and N. McPherson: Mater. Des., 2014, vol. 62, pp. 64-75.

50. T.N. Baker and N.A. McPherson: Mater. Sci. Technol., 2016, vol. 33, pp. 234- 43.

51. H.H. Cho, H.N. Han, S.T. Hong, J.H. Park, Y.J. Kwon, S.H. Kim, and R.J. Steel: Mater. Sci. Eng. A, 2011, vol. 528, pp. 2889-94.

52. H.H. Cho, S.H. Kang, S.H. Kim, K.H. Oh, H.J. Kim, W.S. Chang, and H.N. Han: Mater. Des., 2012, vol. 34, pp. 258-67.

53. D.P. Field, T.W. Nelson, Y. Hovanski, and K.V. Jata: Metall. Mater. Trans. A, 2001, vol. 32, pp. 2869-77.

54. Y.S. Sato, H. Kokawa, K. Ikeda, M. Enomoto, S. Jogan, and T. Hashimoto: Metall. Mater. Trans. A, 2001, vol. 32, pp. 941-48.

55. M.M.Z. Ahmed, B.P. Wynne, W.M. Rainforth, and P.L. Threadgill: Scr. Mater., 2008, vol. 59, p. 507.

56. P.S. Davies, B.P. Wynne, W.M. Rainforth, M.J. Thomas, and P.L. Threadgill: Metall. Mater. Trans. A, 2011, vol. 42, pp. $2278-89$.

57. S. Mironov, Y.S. Sato, and H. Kokawa: Acta Mater., 2008, vol. 56, pp. 2602-14.

58. B. D. Nelson, Using Design of Experiments and Electron Backscatter Diffraction to Model Extended Plasticity Mechanisms in Friction Stir Welded AISI 304L Stainless Steel, Brigham Young University, 2010

59. M. E. Fitzpatrick, A. T. Fry, P. Holdway, F. A. Kandil, J. Shackleton and L. Suominen, NPL Measurement Good Practice Guide No. 52, 2005.

60. S. Rajakumar, C. Muralidharan, and V. Balasubramanian: Mater. Des., 2011, vol. 32, pp. 535-49.

61. Y.G. Kim, H. Fujii, T. Tsumura, T.T. Komazaki, and K. Nakata: Mater. Sci. Eng. A, 2006, vol. 415, pp. 250-54.

62. E. J. Gutie' rrez-Castan eda n, A. Salinas-Rodr1'guez, J Magn Magn Mater 2011, vol. 323, pp. 2524-30.

63. D.H. Choi, C.Y. Lee, B.W. Ahn, Y.M. Yeon, S.H.C. Park, Y.S. Sato, H. Kokawa, and S.B. Jung: Sci. Technol. Weld. Join., 2010, vol. 15 , pp. $299-304$

64. L. Gavard, H.K.D.H. Bhadeshia, D.J.C. Mackay, and S. Suzuki: Mater. Sci. Technol., 1996, vol. 12, pp. 453-63.

65. H. Sieurin and R. Sandström: Mater. Sci. Eng. A, 2006, vol. 418, pp. $250-56$. 
66. N.A. McPherson, Y. Li, and T.N. Baker: Sci. Technol. Weld. Join., 2010, vol. 5, pp. 235-44.

67. R. Badji, M. Bouabdallah, B. Bacroix, C. Kaloun, B. Belkessa, and H. Maza: Mater. Charact., 2008, vol. 59, pp. 447-53.

68. V. Muthupandi, P. Bala Srinivasan, S.K. Seshadri, and S. Sundaresan: Mater. Sci. Eng. A, 2003, vol. 358, pp. 9-16.

69. J.R. Yang and H.K.D.H. Bhadeshia: Adv Weld Technol Sci, 1987, vol. 1, pp. 187-91.

70. R.A. Farrar and P.L. Harrison: J Mater Sci, 1987, vol. 22, pp. 3812-20.

71. A. Iza-Mendia, A. Pinol-Juez, J.J. Urcola, and I. Gutierrez: Metall. Mater. Trans. A, 1998, vol. 29, pp. 2975-86.

72. A. Pinol-Juez, A. Iza-Mendia, and I. Gutierrez: Metall. Mater. Trans. A, 2000, vol. 31, pp. 1671-77.

73. G. Martin, D. Caldemaison, M. Bornert, C. Pinna, Y. Brechet, M. Veron, J.D. Mithieux, and T. Pardoen: Exp. Mech., 2013, vol. 53, pp. 205-15.

74. G. Martin, S.K. Yerra, Y. Brechet, M. Veron, J.D. Mithieux, B. Chehab, L. Delannay, and T. Pardoen: Acta Mater., 2012, vol. 60, pp. 4646-60.

75. L. Duprez, B.C. De Cooman, and N. Akdut: Metall. Mater. Trans. A, 2002, vol. 33, pp. 1931-38.

76. L.E. Hernandez-Castillo, J.H. Beynon, C. Pinna, and S. Van Der Zwaag: Steel Res. Int., 2005, vol. 76, pp. 137-41.

77. F.J. Humphreys and M. Hatherly: Recrystallization and Related Annealing Phenomena, 2nd ed., Elsevier Science, New York, 2004.

78. P. Cizek, B.P. Wynne, and W.M. Rainforth: Mater. Sci. Eng. A, 2002, vol. 324, pp. 214-18.

79. P. Cizek, F. Bai, W.M. Rainforth, and J.H. Beynon: Mater. Trans. JIM, 2004, vol. 45, pp. 1-8.

80. S. Gourdet and F. Montheillet: Acta Mater., 2003, vol. 51, pp. 2685-99.

81. A. Dehghan-Manshadi, M.R. Barnett, and P.D. Hodgson: Mater. Sci. Technol., 2007, vol. 23, pp. 1478-84.

82. A. Oudin, P.D. Hodgson, and M.R. Barnett: Mater. Sci. Eng. A, 2008, vol. 486, pp. 72-79.

83. C. Castan, F. Montheillet, and A. Perlade: Scr. Mater., 2013, vol. 68 , pp. $360-64$.

84. C.G. Schmidt, C.M. Young, B. Walser, R.H. Klundt, and O.D. Sherby: Metall. Trans. A, 1982, vol. 13, pp. 447-56.

85. C. Huang, E.B. Hawbolt, X. Chen, T.R. Meadowcroft, and D.K. Matlock: Acta Mater., 2001, vol. 49, pp. 1445-52.

86. F. Gao, Y. Xu, B. Song, and K. Xia: Metall. Mater. Trans. A, 2000, vol. 31, pp. 21-27.

87. J. Baczynski and J.J. Jonas: Metall. Mater. Trans. A, 1998, vol. 29, pp. 447-62.

88. L. Li, W. Yang, and Z. Sun: Metall. Mater. Trans. A, 2006, vol. 37, pp. 609-19.

89. L. Li, W. Yang, and Z. Sun: Metall. Mater. Trans. A, 2013 , vol. 44, pp. 2060-69.

90. O. Balancin, W.A.M. Hoffmann, and J.J. Jonas: Metall. Mater. Trans. A, 2000, vol. 31, pp. 1353-64.

91. P. Cizek and B.P. Wynne: Mater. Sci. Eng. A, 1997, vol. 230, pp. 88-94.

92. P. Cizek, B.P. Wynne, and W.M. Rainforth: J. Microsc., 2006, vol. 222, pp. $85-96$.
93. R.Z. Wang and T.C. Lei: Scr. Metall. Mater., 1994, vol. 31, pp. 1193-96.

94. T. Maki, T. Furuhara, and T. Tsuzaki: ISIJ Int., 2001, vol. 41, pp. 571-79.

95. P. Cizek, B.P. Wynne, and W.M. Rainforth: Acta Mater., 2016, vol. 106, pp. 129-43.

96. N. Haghdadi, P. Cizek, H. Beladi, and P.D. Hodgson: Acta Mater., 2017, vol. 126, pp. 44-57.

97. H.J. McQueen: Mater. Sci. Eng. A, 2004, vols. 387-389, pp. 203-208.

98. T. Sakai and J.J. Jonas: Acta Metall, 1984, vol. 32, pp. 189-209.

99. E. Brunger, X. Wang, and G. Gottstein: Scr. Mater., 1998, vol. 38, pp. 1843-49.

100. H. Beladi, P. Cizek, and P.D. Hodgson: Metall. Mater. Trans. A, 2009, vol. 40, pp. 1175-89.

101. H. Beladi, P. Cizek, and P.D. Hodgson: Scr. Mater., 2009, vol. 61, pp. 528-31.

102. H. Beladi, P. Cizek, and P.D. Hodgson: Acta Mater., 2010, vol. 58, pp. 3531-41.

103. N. Haghdadi, P. Cizek, H. Beladi, and P.D. Hodgson: Philos. Mag., 2017, vol. 97, pp. 1209-37.

104. D. Poddar, P. Cizek, H. Beladi, and P.D. Hodgson: Metall. Mater. Trans. A, 2015, vol. 46, pp. 5933-51.

105. A.P. Reynolds, W. Tang, T. Gnaupel-Herold, and H. Prask: Scr. Mater., 2003, vol. 48, pp. 1289-94.

106. H.K.D.H. Bhadeshia and T. Debroy: Sci. Technol. Weld. Join., 2009, vol. 14, pp. 193-96.

107. U.F.H.R. Suhuddin, S. Mironov, Y.S. Sato, H. Kokawa, and C.W. Lee: Acta Mater., 2009, vol. 57, pp. 5406-18.

108. Y.S. Sato, H. Yamanoi, H. Kokawa, and T. Furuhara: Scr. Mater., 2007, vol. 57, pp. 557-60.

109. T. Saeid, A. Abdollah-zadeh, T. Shibayanagi, K. Ikeuchi, and H. Assadi: Mater. Sci. Eng. A, 2010, vol. 527, pp. 6484-88.

110. J. Johansson, M. Ode'n, X. H. Zeng, Acta Mater. 1999, vol. 47, pp. 2669-84.

111. J. Johansson, M. Ode'n, Metall. Mater. Trans. A 2000, vol. 31, pp. $1557-70$

112. P.B. Prangnell and C.P. Heason: Acta Mater., 2005, vol. 53, pp. 3179-92.

113. R.W. Fonda, J.F. Bingert, and K.J. Colligan: Scr. Mater., 2004, vol. 51 , pp. $243-48$.

114. R.W. Fonda and K.E. Knipling: Sci. Technol. Weld. Join., 2011, vol. 16, pp. 288-94.

115. K.E. Knipling and R.W. Fonda: Scr. Mater., 2009, vol. 60, pp. 1097-1100.

116. C.S. Lee and B.J. Duggan: Acta Metall. Mater., 1993, vol. 9, pp. 2691-99.

117. D. Raabe, Z. Zhao, S.J. Park, and F. Roters: Acta Mater., 2002, vol. 50 , pp. $421-40$.

118. A. Celik and A. Alsaran: Mater. Charact., 1999, vol. 43, pp. 311-38.

119. J. Wang, M. Lu, L. Zhang, W. Chang, L. Xu, and L. Hu: Int. J. Miner. Metall. Mater., 2012, vol. 19, pp. 518-24.

120. S. Meco, G. Pardal, S. Ganguly, S. Williams, and N. McPherson: Opt. Lasers Eng., 2015, vol. 67, pp. 22-30.

121. S.W. Banovic, J.N. DuPont, and A.R. Marder: Sci. Technol. Weld. Join., 2002, vol. 7, pp. 374-83. 